\title{
Microwave radiometer to retrieve temperature profiles from the surface to the stratopause
}

\author{
O. Stähli ${ }^{1}$, A. Murk ${ }^{1}$, N. Kämpfer ${ }^{1,2}$, C. Mätzler ${ }^{1,2}$, and P. Eriksson ${ }^{3}$ \\ ${ }^{1}$ Institute of Applied Physics, University of Bern, Bern, Switzerland \\ ${ }^{2}$ Oeschger Centre for Climate Change Research, University of Bern, Bern, Switzerland \\ ${ }^{3}$ Department of Earth and Space Sciences, Chalmers University of Technology, Göteborg, Sweden
}

Correspondence to: O. Stähli (oliver.staehli@iap.unibe.ch)

Received: 6 March 2013 - Published in Atmos. Meas. Tech. Discuss.: 21 March 2013

Revised: 29 July 2013 - Accepted: 7 August 2013 - Published: 25 September 2013

\begin{abstract}
TEMPERA (TEMPERature RAdiometer) is a new ground-based radiometer which measures in a frequency range from $51-57 \mathrm{GHz}$ radiation emitted by the atmosphere. With this instrument it is possible to measure temperature profiles from ground to about $50 \mathrm{~km}$. This is the first groundbased instrument with the capability to retrieve temperature profiles simultaneously for the troposphere and stratosphere. The measurement is done with a filterbank in combination with a digital fast Fourier transform spectrometer. A hot load and a noise diode are used as stable calibration sources. The optics consist of an off-axis parabolic mirror to collect the sky radiation. Due to the Zeeman effect on the emission lines used, the maximum height for the temperature retrieval is about $50 \mathrm{~km}$. The effect is apparent in the measured spectra. The performance of TEMPERA is validated by comparison with nearby radiosonde and satellite data from the Microwave Limb Sounder on the Aura satellite. In this paper we present the design and measurement method of the instrument followed by a description of the retrieval method, together with a validation of TEMPERA data over its first year, 2012.
\end{abstract}

\section{Introduction}

Temperature is a key parameter for dynamical, chemical and radiative processes in the atmosphere. There exist several techniques to measure atmospheric temperature profiles like radiosonde (e.g. Luers, 1997; Ruffieux and Joss, 2003), FTIR (Fourier transform infrared, e.g. Smith et al., 1999; Feltz et al., 2003), lidar (e.g. Evans et al., 1997; Alpers et al.,
2004), GPS occultation (e.g. Wickert et al., 2001; Hajj et al., 2002) or satellite and ground-based microwave radiometers (for examples see below). The advantage of ground-based radiometry is the high time resolution at a fixed location that allows for observing local atmospheric dynamics over a long time period. Furthermore, in the near future there might be a lack of satellites which are measuring middle atmospheric profiles of trace gases and temperature. Therefore groundbased radiometry is important to continuously observe the atmosphere.

In the troposphere the atmospheric temperature is important for weather fore- and now-casting. Ground-based microwave radiometers for tropospheric temperature profiles are well established and exist in different configurations. Examples are MICCY (microwave radiometer for cloud cartography) (Crewell et al., 2001), RPG-HATPRO (Radiometer Physics GmbH-Humidity and Temperature Profiler) (Rose et al., 2005), Radiometrics MP-3000A (Ware et al., 2003) and ASMUWARA (All-Sky MUlti WAvelength RAdiometer) (Martin et al., 2006).

In the stratosphere temperature can influence chemical processes, and the vertical temperature distribution is important for atmospheric studies to investigate, for example, ozone or water vapor. The middle atmospheric temperature profile also can be affected by dynamical processes such as during sudden stratospheric warming (SSW, e.g. Scherhag, 1952; Flury et al., 2009; Scheiben et al., 2012) events when the temperature in the stratosphere can change by several tens of degrees within a very short time. Therefore it is necessary to obtain temperature profiles with a good temporal and spatial resolution. At present, data of stratospheric temperature 


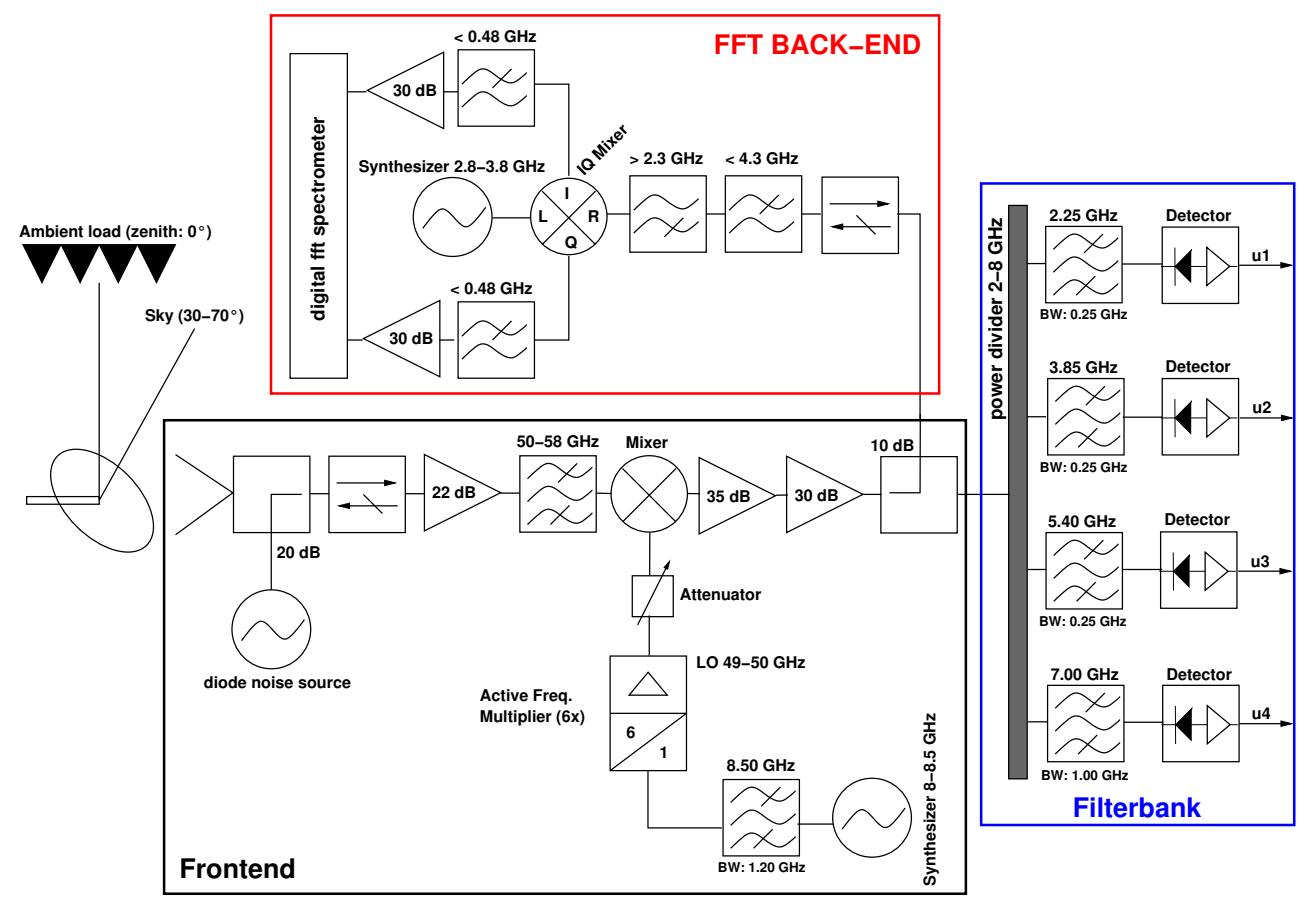

Fig. 1. TEMPERA block diagram.

profiles are mostly obtained by remote sensing methods using radiometers on satellites (e.g. MLS instrument on the Aura satellite as described in Waters et al. (2006), AMSUA instrument on the Aqua satellite as described in Aumann et al. (2003) and SABER instrument on the TIMED satellite as described in Remsberg et al. (2003)).

The possibility of ground-based measurements of stratospheric thermal emission from high-rotational, magnetic dipole transitions of molecular oxygen around $53 \mathrm{GHz}$ was first shown in Waters (1973). It is interesting to note that no realization of a ground-based stratospheric temperature radiometer was reported in the literature for several decades. A recent realization of such an instrument was described by Shvetsov et al. (2010).

In this paper we describe the construction, calibration and utilization of a new ground-based TEMPERature RAdiometer, called TEMPERA, that is able to monitor temperature structures from ground to the upper stratosphere.

In the following section of this paper we present the measurement method and the instrumental set-up of TEMPERA. In the third section we describe the temperature retrieval. In the fourth section a validation of the TEMPERA data and comparison with radiosonde and satellite data is presented.

\section{Measurement method and instrument description}

\subsection{Measurement method}

TEMPERA measures thermal radiation from $51-57 \mathrm{GHz}$ in the oxygen-emission region of the microwave spectrum. Oxygen is a well-mixed gas whose fractional concentration is independent of altitude below approx. $80 \mathrm{~km}$. Therefore the radiation contains information primarily on atmospheric temperature.

For tropospheric temperature profiles we measure with a filterbank at 12 frequencies from $51-57 \mathrm{GHz}$ on the wing of the $60 \mathrm{GHz}$ oxygen emission complex. In addition, with a digital fast Fourier transform (FFT) spectrometer, we get information on the temperature profile in the stratosphere by measuring two pressure-broadened emission lines centered at 52.5424 and $53.0669 \mathrm{GHz}$.

A ground-based microwave radiometer measures a superposition of emission and absorption of radiation at different altitudes. The intensity $I$ can be described with the radiative transfer equation:

$I(\nu, 0)=I_{0} e^{-\tau\left(\nu, s_{0}\right)}+\int_{0}^{s_{0}} B(\nu, T(s)) e^{-\tau(\nu, s)} \alpha(\nu, s) \mathrm{d} s$,

where $I(v, 0)$ is the measured intensity at frequency $v$ from an observation position 0 at the earth surface, $I_{0}$ is the microwave background intensity, $s_{0}$ is the position of the upper boundary of the atmosphere, $T(s)$ is the physical temperature and $\alpha(\nu, s)$ is the frequency-dependent absorption 


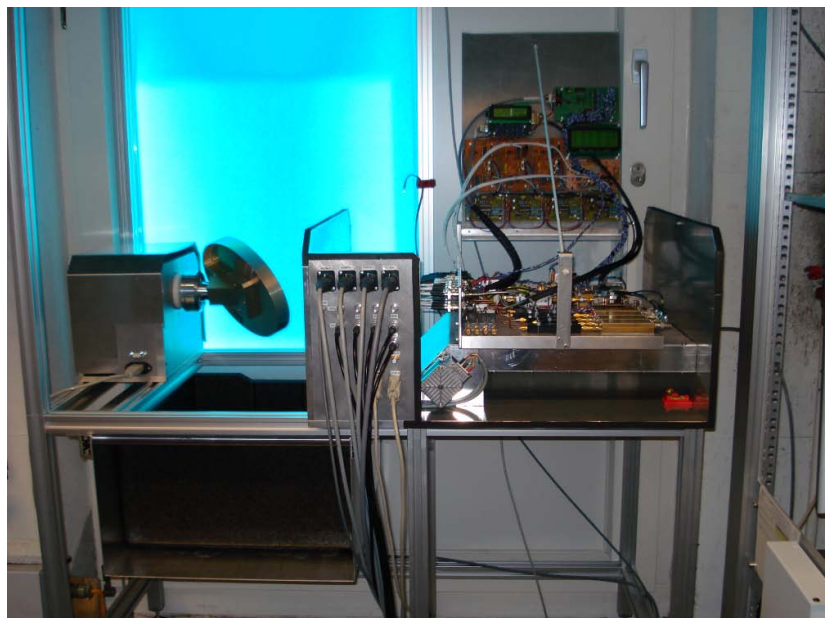

Fig. 2. TEMPERA with its main components, the frontend and the parabolic mirror. TEMPERA is $1.1 \mathrm{~m}$ wide. The instrument is placed inside in a thermally controlled lab in front of a blue styrofoam window through which the atmosphere is observed.

coefficient both along the integration path $s . B(v, T)$ is the Planck function:

$B(v, T)=\frac{2 h v^{3}}{c^{2}} \frac{1}{e^{\frac{h v}{k T}-1}}$,

where $h$ is the Planck's constant, $k$ is the Boltzmann's constant and $c$ is the speed of light.

The opacity or optical depth $\tau$ is defined as

$\tau(v, s)=\int_{0}^{s} \alpha\left(v, s^{\prime}\right) \mathrm{d} s^{\prime}$.

In microwave radiometry the measured intensity of radiation is often expressed as brightness temperature $T_{\mathrm{B}}$ according to the Rayleigh-Jeans approximation (valid for the case $h v \ll k T)$ of Planck's law:

$T_{\mathrm{B}}(\nu, 0)=\frac{\lambda^{2}}{2 k} I(\nu, 0)$,

where $\lambda$ is the wavelength.

The measured spectrum $T_{\mathrm{B}}(v, 0)$ is used to retrieve the temperature profile, as described in Sect. 3.1.

\subsection{Instrumental description}

TEMPERA is a heterodyne receiver covering a frequency range of $51-57 \mathrm{GHz}$. Figures 1 and 2 give an overview of the instrument. Our instrument consists of three parts: the frontend to collect and detect the microwave radiation with two backends, a filterbank and a digital FFT spectrometer for the spectral analysis. The radiation is directed into the corrugated horn antenna using an off-axis parabolic mirror. The antenna beam has a half-power beamwidth (HPBW) of $4^{\circ}$. The signal is then amplified and downconverted to an intermediate frequency for further spectral analysis. A noise diode in combination with an ambient hot load is used for calibration. The hot load has the room temperature of the laboratory (around $293 \mathrm{~K}$ ). The receiver noise temperature $T_{\mathrm{N}}$ is in a range from $475-665 \mathrm{~K}$. An overview of the technical specifications is given in Table 1 .

For the tropospheric measurements we use a filterbank (first backend) with 4 channels. However in the end we actually measure at 12 frequencies, which are listed in Table 2 , by adjusting the local oscillator (LO) frequency with a synthesizer. For every measured zenith angle the LO frequency is changed three times. In this way we uniformly cover the range from $51-57 \mathrm{GHz}$ at positions between the emission lines (see Fig. 3). The lower 9 channels have a bandwidth of $250 \mathrm{MHz}$ and the channels $10-12$ have a bandwidth of $1 \mathrm{GHz}$ to enhance the sensitivity in the flat spectral region.

The second backend is used for stratospheric measurements and contains a digital FFT spectrometer (Acqiris AC240) for the two emission lines centered at 52.5424 and $53.0669 \mathrm{GHz}$. The input signal is coupled from the main signal before the filterbank. It passes an IQ-Mixer (Murk et al., 2009) before being fed to the spectrometer. When the LO frequency is changed by the synthesizer in the frontend, the second synthesizer, which is placed in front of the IQ-Mixer, also changes the frequency. With this method we can always measure the same range with the FFT spectrometer. Furthermore, this allows us to measure the tropospheric and stratospheric part at the same time. With the FFT spectrometer in combination with the IQ-Mixer, we can measure the two emission lines with a resolution of $30.5 \mathrm{kHz}$ and a bandwidth of $960 \mathrm{MHz}$. The receiver noise temperature $T_{\mathrm{N}}$ for the receiver-spectrometer combination is around $480 \mathrm{~K}$. In Table 2 a list with all channels and the corresponding frequencies, bandwidths and the receiver noise temperatures is given.

An example of a measured spectrum is shown in Fig. 4. The zoomed lines show the influence of the Zeeman effect by the broadened line shape in the center with a kind of a plateau (round line shape around the line center: $\pm 1 \mathrm{MHz}$ ).

TEMPERA operates from a temperature-stabilized laboratory at the ExWi Building of the University of Bern (Bern, Switzerland: $575 \mathrm{~m}$ above sea level; $46.95^{\circ} \mathrm{N}, 7.44^{\circ} \mathrm{E}$, view direction in azimuth: southeast $\left(131.5^{\circ}\right)$ ). A styrofoam window allows views of the atmosphere over the zenith angle (za) range from $30^{\circ}$ to $70^{\circ}$. The operation of the instrument inside a laboratory has the advantage that the radiometer is protected against adverse weather conditions. The frontend itself has additional temperature stabilization with Peltier elements in combination with a ventilation system leading to a stabilization of the frontend plate within $\pm 0.2 \mathrm{~K}$. 
Table 1. Specifications of TEMPERA.

\begin{tabular}{ll}
\hline Optical system & Corrugated horn antenna with parabolic mirror, HPBW=4 \\
Receiver type & Uncooled heterodyne receiver, filterbank; digital FFT spectrometer \\
RF frequency range & Filterbank: 51-57 GHz, FFT spectrometer: 52.4-53.2 GHz \\
Receiver operation mode & Single sideband \\
Receiver noise temperature & $475-665 \mathrm{~K}$ \\
Filterbank & 4 filters, bandwidth $250 \mathrm{MHz}$ and $1 \mathrm{GHz}$ \\
FFT Spectrometer & Bandwidth $1 \mathrm{GHz}$, resolution $30.5 \mathrm{kHz}, 32768$ channels \\
Mixer (FFT-Backend) & I/Q \\
Calibration & Hot load, noise diode \\
\hline
\end{tabular}

Table 2. Specifications of the 12 tropospheric channels (ch1-ch12) and of the FFT spectrometer (ch_fft) with frequency $f$, the bandwidth $B$ and receiver noise temperature $T_{\mathrm{N}}$.

\begin{tabular}{ccccccccc}
\hline channel & $f[\mathrm{GHz}]$ & $B[\mathrm{MHz}]$ & $T_{\mathrm{N}}[\mathrm{K}]$ & & channel & $f[\mathrm{GHz}]$ & $B[\mathrm{MHz}]$ & $T_{\mathrm{N}}[\mathrm{K}]$ \\
\hline 1 & 51.25 & 250 & 475 & & 8 & 54.90 & 250 & 560 \\
2 & 51.75 & 250 & 540 & & 9 & 55.40 & 250 & 570 \\
3 & 52.25 & 250 & 585 & & 10 & 56.00 & 1000 & 555 \\
4 & 52.85 & 250 & 495 & & 11 & 56.50 & 1000 & 625 \\
5 & 53.35 & 250 & 550 & & 12 & 57.00 & 1000 & 665 \\
6 & 53.85 & 250 & 555 & & & & & \\
7 & 54.40 & 250 & 480 & & $\mathrm{fft}$ & $52.4-53.2$ & 800 & 480 \\
\hline
\end{tabular}

\subsection{Measurement cycle}

Measurements are performed in periodic cycles with periods of $60 \mathrm{~s}$. Each cycle starts with hot load calibration in combination with a noise diode (see also Sect. 2.4) for $9 \mathrm{~s}$ followed by the atmosphere measurements. They consist of two parts: first a $15 \mathrm{~s}$ period at a zenith angle $\mathrm{za}=30^{\circ}$ to observe with the FFT spectrometer and simultaneously with the filterbank, and second, a tipping curve in $3 \mathrm{~s}$ periods and angular steps in $5^{\circ}$ up to $\mathrm{za}=70^{\circ}$.

After calibration, the output of each measurement cycle is a set of 108 brightness temperatures of the filterbank at 12 frequencies and at 9 zenith angles and a calibrated spectrum at the two emission lines from the FFT spectrometer consisting of 32768 channels covering the bandwidth of $960 \mathrm{MHz}$.

For the retrieval we use a mean of 15 measurement cycles for the troposphere and 120 measurement cycles for the stratosphere, leading to a time resolution of $15 \mathrm{~min}$ for tropospheric profiles and $120 \mathrm{~min}$ for stratospheric profiles.

\subsection{Calibration}

Under the assumption of linearity between the antenna temperature $T_{\mathrm{A}}$ and the detector-output voltage $V_{T_{\mathrm{A}}}$, as well as the assumption of a perfect antenna that the brightness temperature $T_{\mathrm{B}}$ is equal to $T_{\mathrm{A}}$, the following relation is valid:

$T_{\mathrm{B}}=T_{\mathrm{A}}=\frac{V_{T_{\mathrm{A}}}}{g}-T_{\mathrm{N}}$, where $g$ is the effective gain factor and $T_{\mathrm{N}}$ is the receiver noise temperature.

The calibration parameters $g$ and $T_{\mathrm{N}}$ are obtained from the known radiation of an ambient hot load in combination with a noise diode.

To calibrate the noise diode we use a hot and a cold load. The cold load is a microwave absorber dipped in liquid nitrogen. Both loads are pyramidal microwave absorbers. With this calibration the so-called excess-noise diode temperature $T_{\mathrm{ND}}$ is determined:

$T_{\mathrm{ND}}=\left(T_{\mathrm{H}}-T_{\mathrm{C}}\right) \cdot \frac{V_{\mathrm{HND}}-V_{\mathrm{H}}}{V_{\mathrm{H}}-V_{\mathrm{C}}}$,

where $T_{\mathrm{H}}$ is the physical temperature of the hot load, $T_{\mathrm{C}}$ is the physical temperature of the cold load (around $77 \mathrm{~K}$ at an altitude of $575 \mathrm{~m}$, depending on pressure), $V$ is the detectoroutput voltage, index $H$ means hot load, HND means hot load with the noise diode switched on, and $C$ means cold load.

The excess-noise diode temperature $T_{\mathrm{ND}}$ is in a range from 40-75 $\mathrm{K}$ depending on the frequency.

With $T_{\mathrm{ND}}$ we can finally calculate $g$ and $T_{\mathrm{N}}$ :

$g=\frac{V_{\mathrm{HND}}-V_{\mathrm{H}}}{T_{\mathrm{ND}}}$

$T_{\mathrm{N}}=\frac{V_{\mathrm{H}} \cdot\left(T_{H}+T_{\mathrm{ND}}\right)-V_{\mathrm{HND}} \cdot T_{\mathrm{H}}}{V_{\mathrm{HND}}-V_{\mathrm{H}}}$

The excess-noise diode temperature $T_{\mathrm{ND}}$ is stable for more than 4 weeks ( $\Delta T_{\mathrm{ND}}<0.3 \mathrm{~K}$ for all frequencies). Therefore we repeat its calibration with liquid nitrogen every month. 

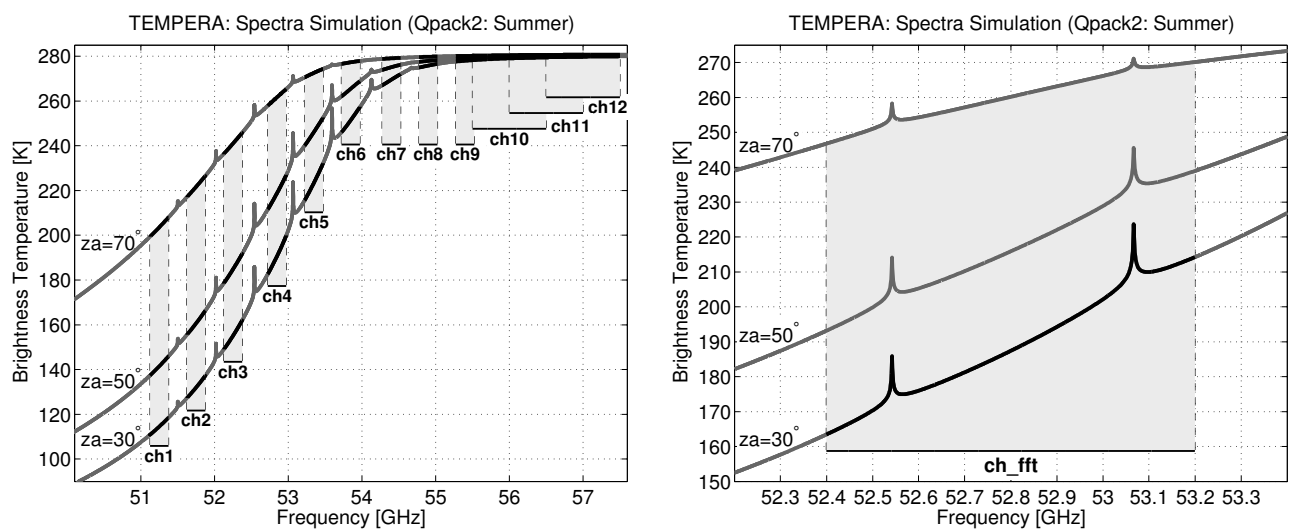

Fig. 3. Left panel: TEMPERA spectrum from $51-57 \mathrm{GHz}$ simulated with Qpack2/ARTS2 during summer for zenith angles at 30,50 and $70^{\circ}$. The grey bars indicate the 12 channels (ch1-ch12) of the filterbank. Right panel: spectrum from 52-53 GHz simulated with Qpack2/ARTS2 during summer for zenith angles of 30,50 and $70^{\circ}$; the grey bar here indicates the available bandwidth of the FFT spectrometer (ch_fft).

TEMPERA: 2012-01-16, Integration: 09:00-13:00
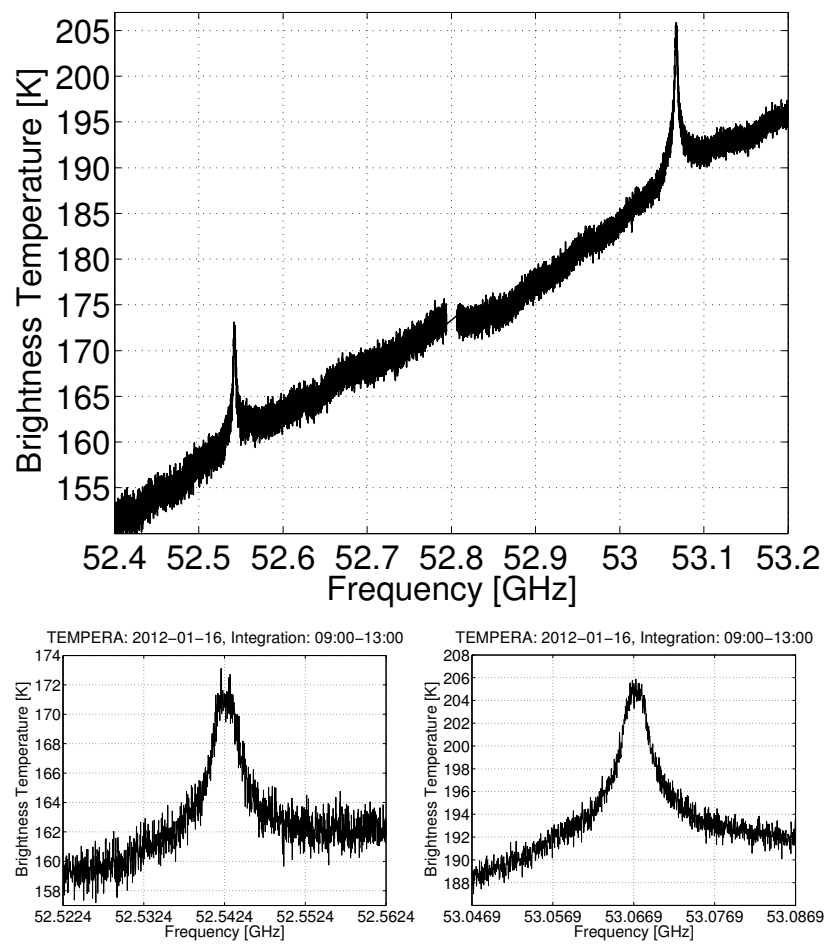

Fig. 4. Spectrum of brightness temperatures measured with TEMPERA on 16 January 2012 from 09:00-13:00 (UT). Upper panel: The whole FFT spectrum, with all channels from 52.4 to $53.2 \mathrm{GHz}$. The gap in the middle is due to effects of the filters. Lower panels: zoomed spectra around the first line at $52.5424 \mathrm{GHz}$ and the second line at $53.0669 \mathrm{GHz}$.

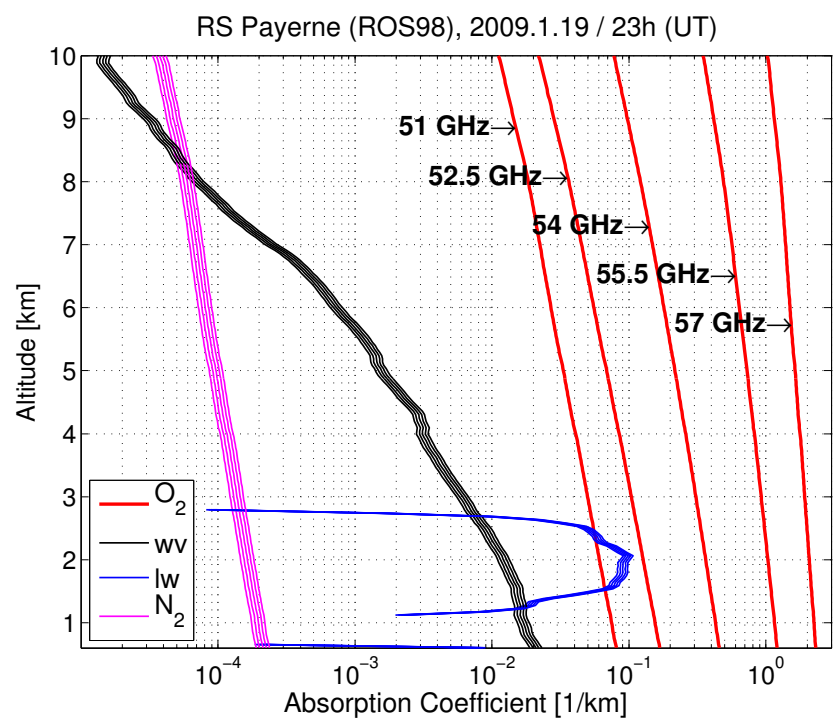

Fig. 5. Absorption Coefficient versus altitude for oxygen $\left(\mathrm{O}_{2}\right)$, water vapor (wv), liquid water (lw) and nitrogen $\left(\mathrm{N}_{2}\right)$ at 51, 52.5, 54, 55.5 and $57 \mathrm{GHz}$ calculated with radiosonde data from Payerne on 19 January 2009 (IWV $=13.11 \mathrm{~mm}$, ILW =0.19 mm). Calculations made with the Rosenkranz (1998) model.

\section{Temperature retrieval}

\subsection{Retrieval}

Our temperature retrieval is based on the optimal estimation method (OEM) (Rodgers, 2000). The forward model $F$, as expressed by Eqs. (1) and (4), is used to simulate our measured brightness temperature. Here we express it in the following equation:

$\boldsymbol{y}=F(\boldsymbol{x}, \boldsymbol{b})+\boldsymbol{\epsilon}$ 
TEMPERA temperature profiles [K] / Retrieval: v12 (tropo), v2 (strato)

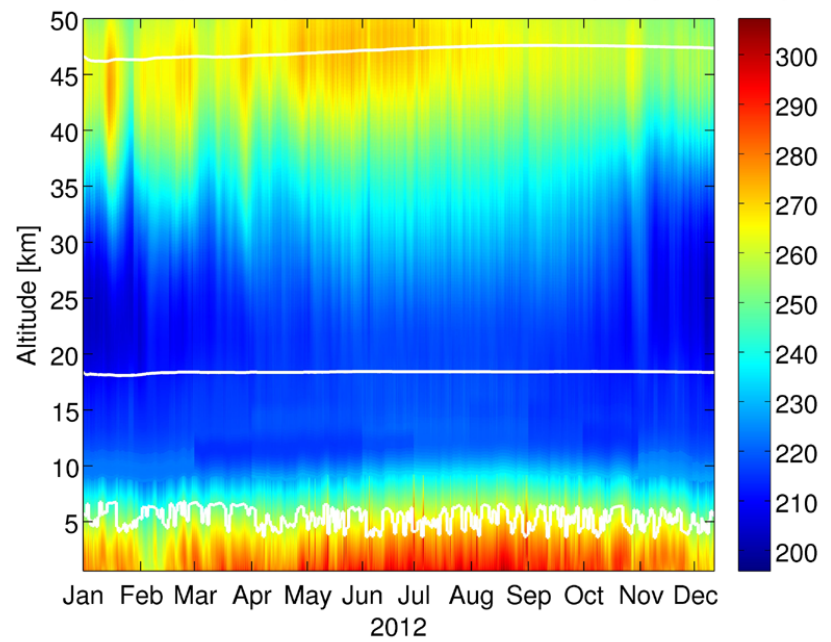

Fig. 6. Temperature profiles derived from TEMPERA from ground to $50 \mathrm{~km}$ from 1 January to 13 December 2012 . The white lines indicate the region where $\mathrm{MR}=0.6$.

where the vector $\boldsymbol{y}$ is the measured spectrum (brightness temperature), $\boldsymbol{x}$ is the true temperature profile, $\boldsymbol{b}$ contains some additional forward model parameters, and $\epsilon$ is the measurement noise. In our case $F$ is nonlinear. To retrieve the temperature profile from the measured brightness temperature, Eq. (9) has to be inverted. This is an ill-posed problem and to obtain an "optimal" solution a statistical constraint is introduced. The solution can be defined as the zero of the gradient of the cost function $J$ :

$J=[\boldsymbol{y}-F(\boldsymbol{x})]^{\mathrm{T}} \mathbf{S}_{\epsilon}^{-1}[\boldsymbol{y}-F(\boldsymbol{x})]+\left[\boldsymbol{x}-\boldsymbol{x}_{\mathrm{a}}\right]^{\mathrm{T}} \mathbf{S}_{\mathrm{a}}^{-1}\left[\boldsymbol{x}-\boldsymbol{x}_{\mathrm{a}}\right]$,

where $\boldsymbol{x}_{\mathrm{a}}$ is the a priori temperature profile, $\mathbf{S}_{\mathrm{a}}$ is the a priori covariance matrix and $\mathbf{S}_{\epsilon}$ is the observation error-covariance matrix.

This principle is based on Bayes' probability theorem. It is assumed that measurement uncertainties $\left(\mathbf{S}_{\epsilon}\right)$ and a priori knowledge $\left(\mathbf{S}_{\mathrm{a}}\right)$ both follow Gaussian statistics. On the condition that the forward model is not strongly nonlinear, the posterior distribution is then also Gaussian. The solution, $\hat{\boldsymbol{x}}$, is taken as the state with highest probability, which for Gaussian statistics is also the expected value of the distribution.

To find the zero of the derivative of the cost function $J$ (Eq. 10) we use the Gauss-Newton iterative method, leading to

$$
\begin{aligned}
\boldsymbol{x}_{i+1} & =\boldsymbol{x}_{i}+\left(\mathbf{S}_{\mathrm{a}}^{-1}+\mathbf{K}_{i}^{\mathrm{T}} \mathbf{S}_{\epsilon}^{-1} \mathbf{K}_{i}\right)^{-1}\left[\mathbf{K}_{i}^{\mathrm{T}} \mathbf{S}_{\epsilon}^{-1}\left(\boldsymbol{y}-F\left(\boldsymbol{x}_{i}\right)\right)\right. \\
& \left.-\mathbf{S}_{\mathrm{a}}^{-1}\left(\boldsymbol{x}_{i}-\boldsymbol{x}_{\mathrm{a}}\right)\right],
\end{aligned}
$$

where $\boldsymbol{x}_{i}$ is the retrieved temperature profile at iteration $i$ and $\mathbf{K}$ is the weighting function $(\mathbf{K}=\partial F / \partial \boldsymbol{x})$.

The radiative transfer calculations are done with the Atmospheric Radiative Transfer Simulator 2 (ARTS2, Eriksson
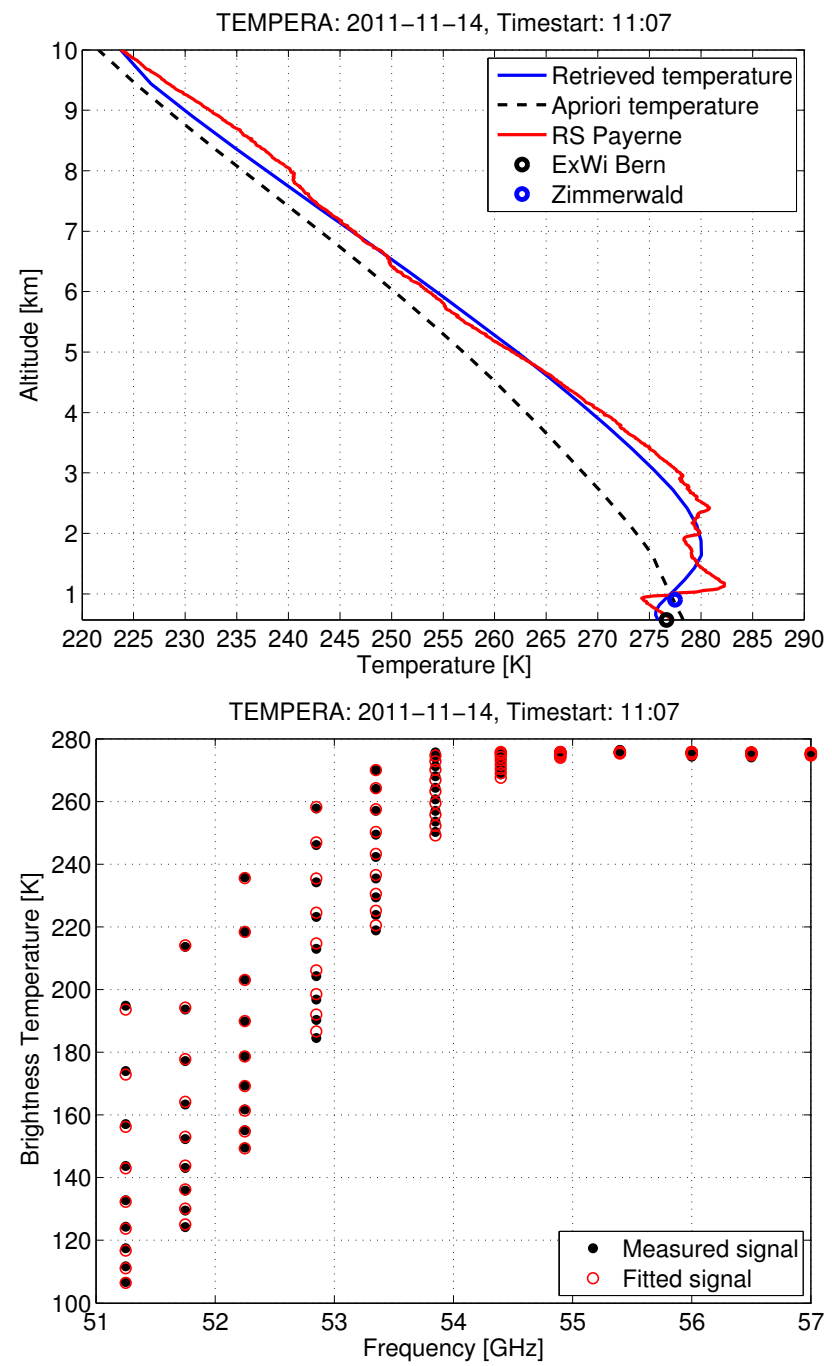

Fig. 7. Measurement of 14 November 2011 at 11:07-11:22 (UT) during clear sky (ILW $=0 \mathrm{~mm}$ ). Upper panel: retrieved temperature profile (blue line). The a priori profile is the dashed black line; comparison with radiosonde data from Payerne (red line), with weather station data from Bern (black circle), and with Zimmerwald (blue circle). Lower panel: brightness temperatures of 12 channels measured with TEMPERA (black dots) compared with the forward model brightness temperatures (open red dots) corresponding to the retrieval.

et al., 2011). The inversion is treated in Qpack2 (Eriksson et al., 2005).

The retrieval is calculated on a pressure grid. We use the same resolution for the retrieval grid as for the forward model grid. In this paper all data are plotted in geometric height in $\mathrm{km}$ for practical reasons. For the conversion from a pressure grid to a kilometer grid we used radiosonde and ECMWF (European Centre for Medium-Range Weather Forecasts) data.

In the OEM method an often used tool is the averaging kernel matrix A (Rodgers, 2000), which describes the response 
Table 3. List of used line parameters for $\mathrm{O}_{2}$. The data are from the PWR93 oxygen absorption model (Rosenkranz, 1993).

\begin{tabular}{ccccccc}
\hline $\begin{array}{c}\text { Quantum } \\
\text { ID }\end{array}$ & $\begin{array}{c}v \\
{[\mathrm{GHz}]}\end{array}$ & $\begin{array}{c}S(300 \mathrm{~K}) \\
{\left[\mathrm{cm}^{2} \mathrm{~Hz}\right]}\end{array}$ & $\begin{array}{c}b \\
{[]}\end{array}$ & $\begin{array}{c}w \\
{\left[\frac{\mathrm{MHz}}{\mathrm{hPa}}\right]}\end{array}$ & $\begin{array}{c}y \\
{\left[\frac{10^{-3}}{\mathrm{hPa}}\right]}\end{array}$ & $\begin{array}{c}v \\
{\left[\frac{10^{-3}}{\mathrm{hPa}}\right]}\end{array}$ \\
\hline $29-$ & 52.5424 & $0.4264 \times 10^{-16}$ & 6.004 & 0.94 & 0.7702 & 0.6526 \\
$27-$ & 53.0669 & $0.8898 \times 10^{-16}$ & 5.224 & 0.97 & 0.7348 & 0.6206 \\
\hline
\end{tabular}
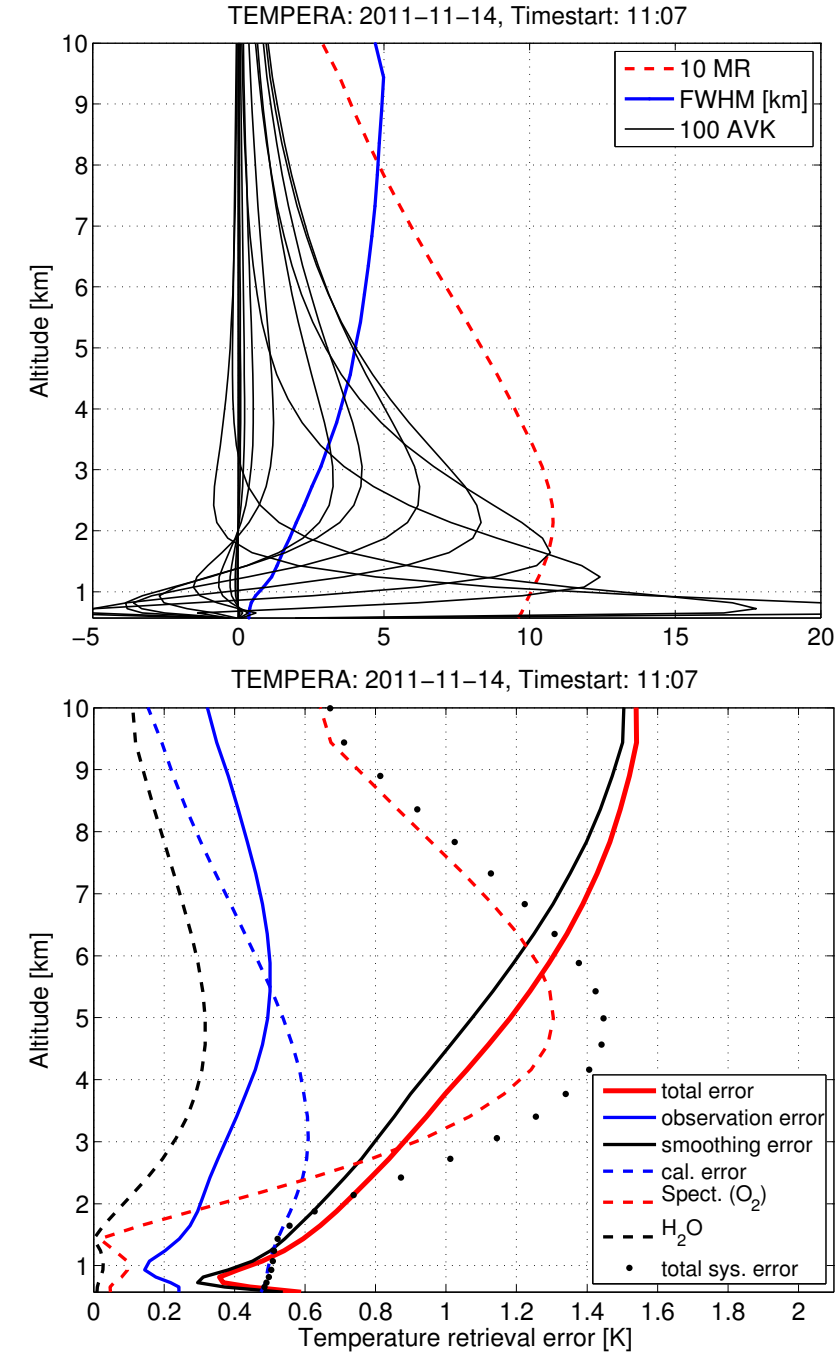

Fig. 8. Measurements of 14 November 2011 at 11:07-11:22 (UT) during clear sky (ILW $=0 \mathrm{~mm}$ ). Upper panel: the averaging kernels (AVK, plotted every 4th) of TEMPERA are shown in this plot together with the measurement response (MR) and the full-width at half-maximum (FWHM, in km). Lower panel: error of the retrieval. The error statistics contain the total error (solid red) consisting of observation error (solid blue) and smoothing error (solid black). The total systematic error (dotted black) contains the uncertainties in the calibration (dashed blue), in the oxygen profile ("spectroscopic error", dashed red) and in the water vapor profile (dashed black).
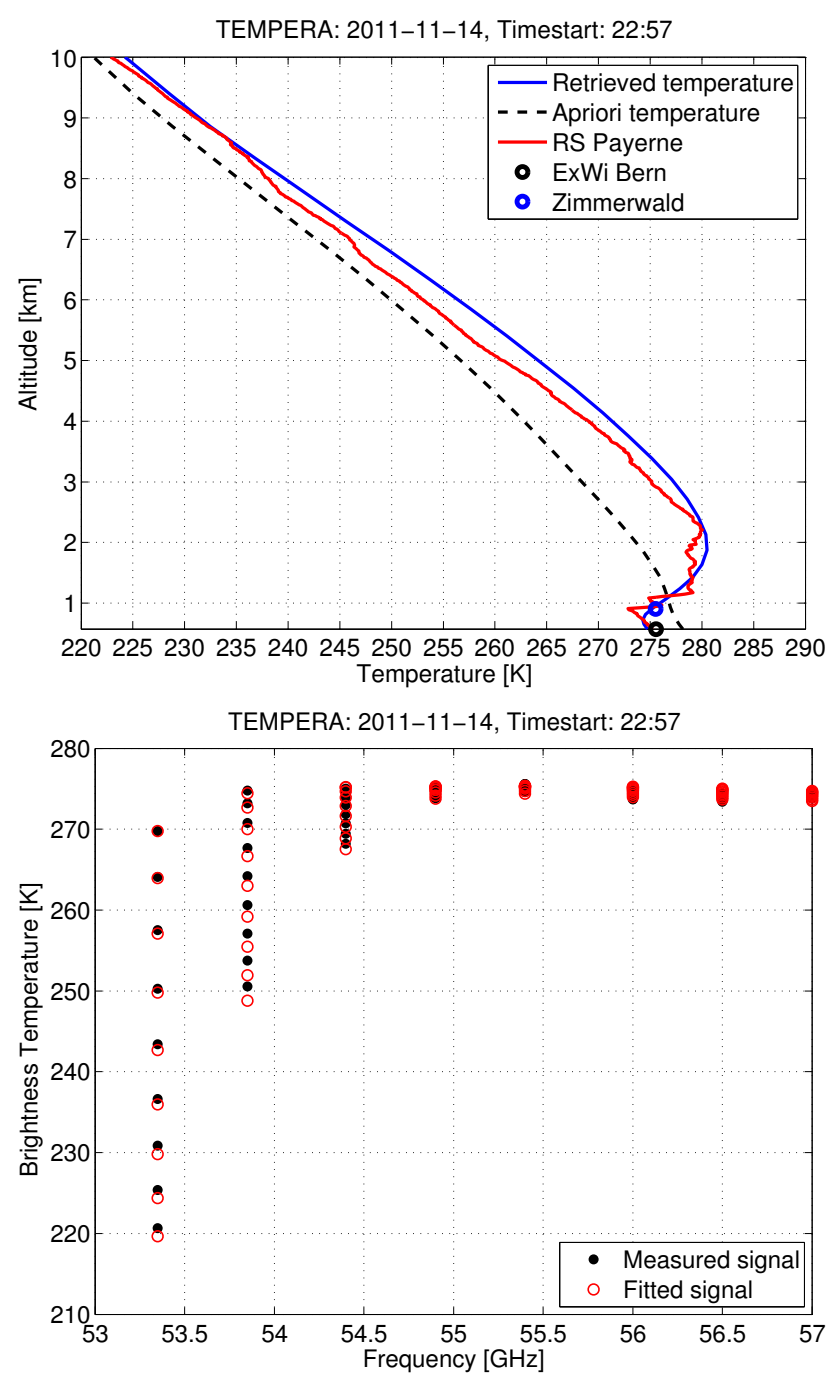

Fig. 9. Measurement of 14 November 2011 at 22:57-23:12 (UT) during cloudy sky (ILW $=0.1 \mathrm{~mm}$ ). Upper panel: temperature profile (blue line) retrieved with TEMPERA. The a priori profile is the dashed black line. The retrieved profile is compared with radiosonde data from Payerne (red line), with weather station data from Bern (black circle), and with Zimmerwald (blue circle). Lower panel: brightness temperatures of 8 channels measured with TEMPERA (black) compared with the forward model brightness temperatures (red) corresponding to the retrieval. 
Table 4. Estimated uncertainties for the calculations of the systematic retrieval errors.

\begin{tabular}{lll}
\hline Troposphere: & Parameter & Uncertainty \\
\hline & Water vapor & $10 \%$ \\
& Oxygen (“spectroscopic error") & $1 \%$ \\
& Calibration & $0.5 \mathrm{~K}$ \\
\hline Stratosphere: & Parameter & Uncertainty \\
\hline & Water vapor & $10 \%$ \\
& Oxygen (“spectroscopic error") & $1 \%$ \\
& Calibration & $1.5 \mathrm{~K}$ \\
\hline
\end{tabular}

of the retrieved temperature profile $\hat{\boldsymbol{x}}$ to a change in the "true" profile $\boldsymbol{x}$ :

$\mathbf{A}=\mathbf{D}_{y} \mathbf{K}_{x}=\frac{\partial \hat{\boldsymbol{x}}}{\partial \boldsymbol{x}}$,

where $\mathbf{K}_{x}=\partial F / \partial \boldsymbol{x}$ is the weighting function matrix and $\mathbf{D}_{y}=\partial \hat{\boldsymbol{x}} / \partial \boldsymbol{y}$ is the contribution function.

The rows of $\mathbf{A}$ are called the averaging kernels (AVK). Every row describes the sensitivity of the retrieval for a certain height level to a perturbation at other levels. The sum of the AVK is called the measurement response (MR), which describes the contribution of measurement to the retrieved profile at a certain height. The full-width at half-maximum (FWHM) of the AVK is often used as a height resolution of the retrieval.

There exist different methods to compare profiles from a ground-based radiometer with a reference profile from collocated radiosondes and satellites. One possibility is to interpolate the reference profiles at levels of the radiometer and compare it directly. A second method is to convolve the interpolated reference profile $\boldsymbol{x}_{\mathrm{r}}$ with the averaging kernel $\mathbf{A}$ of the radiometer to take into account the different height resolutions:

$\hat{\boldsymbol{x}}_{\mathrm{r}}=\boldsymbol{x}_{\mathrm{a}}+\mathbf{A}\left(\boldsymbol{x}_{\mathrm{r}}-\boldsymbol{x}_{\mathrm{a}}\right)$,

where $\boldsymbol{x}_{\mathrm{a}}$ is the a priori profile of the radiometer.

\subsection{Forward model parameters}

In the radiative transfer calculations we use the model of Rosenkranz and the model of Liebe for the absorption coefficient calculations: Rosenkranz (1998) for $\mathrm{H}_{2} \mathrm{O}$, Rosenkranz (1993) for $\mathrm{O}_{2}$ and Liebe et al. (1993) for $\mathrm{N}_{2}$. The used line parameters for the oxygen $\left(\mathrm{O}_{2}\right)$ spectral lines are listed in Table 3.

In the forward model a water-vapor profile with an exponential decrease is included. This profile is calculated with the measured surface water vapor density from the ExWiWeather station (placed next to TEMPERA) and assuming a scale height of $2000 \mathrm{~m}$. Further descriptions can be found in Bleisch et al. (2011). For other species like oxygen $\left(\mathrm{O}_{2}\right)$ and
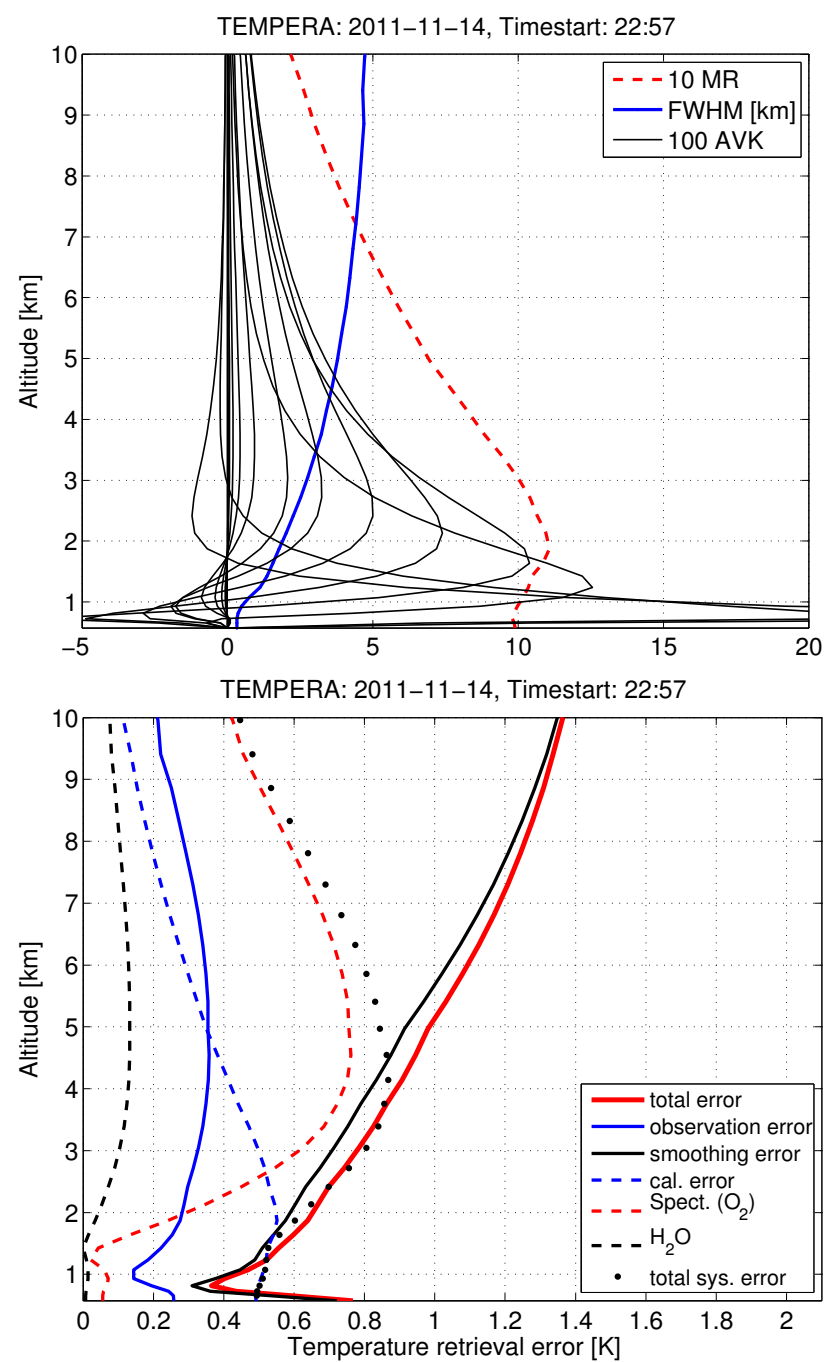

Fig. 10. Measurement of 14 November 2011 at 22:57-23:12 (UT) during cloudy sky (ILW $=0.1 \mathrm{~mm}$ ). Upper panel: the averaging kernels (AVK, plotted every 4th) of TEMPERA are shown in this plot together with the measurements response (MR) and the full-width at half-maximum (FWHM, in km). Lower panel: error of the retrieval. The error statistics contain the total error (solid red) consisting of observation error (solid blue) and smoothing error (solid black). The total systematic error (dotted black) contains the uncertainties in the calibration (dashed blue), in the oxygen profile ("spectroscopic error", dashed red) and in the water vapor profile (dashed black).

nitrogen $\left(\mathrm{N}_{2}\right)$ we used standard atmospheric profiles for summer and winter, which are incorporated into ARTS2 (middle latitude FASCODE (Fast Atmospheric Signature CODE) (Anderson et al., 1986)).

The presence of clouds has a relatively strong influence in the frequency range from 51 to $53 \mathrm{GHz}$, as can be seen in Fig. 5. In this figure the absorption coefficient for water vapor, liquid water, nitrogen and oxygen for 5 different frequencies between 51 and $57 \mathrm{GHz}$ is plotted. The absorption coefficient of the nitrogen, water vapor and the liquid water 


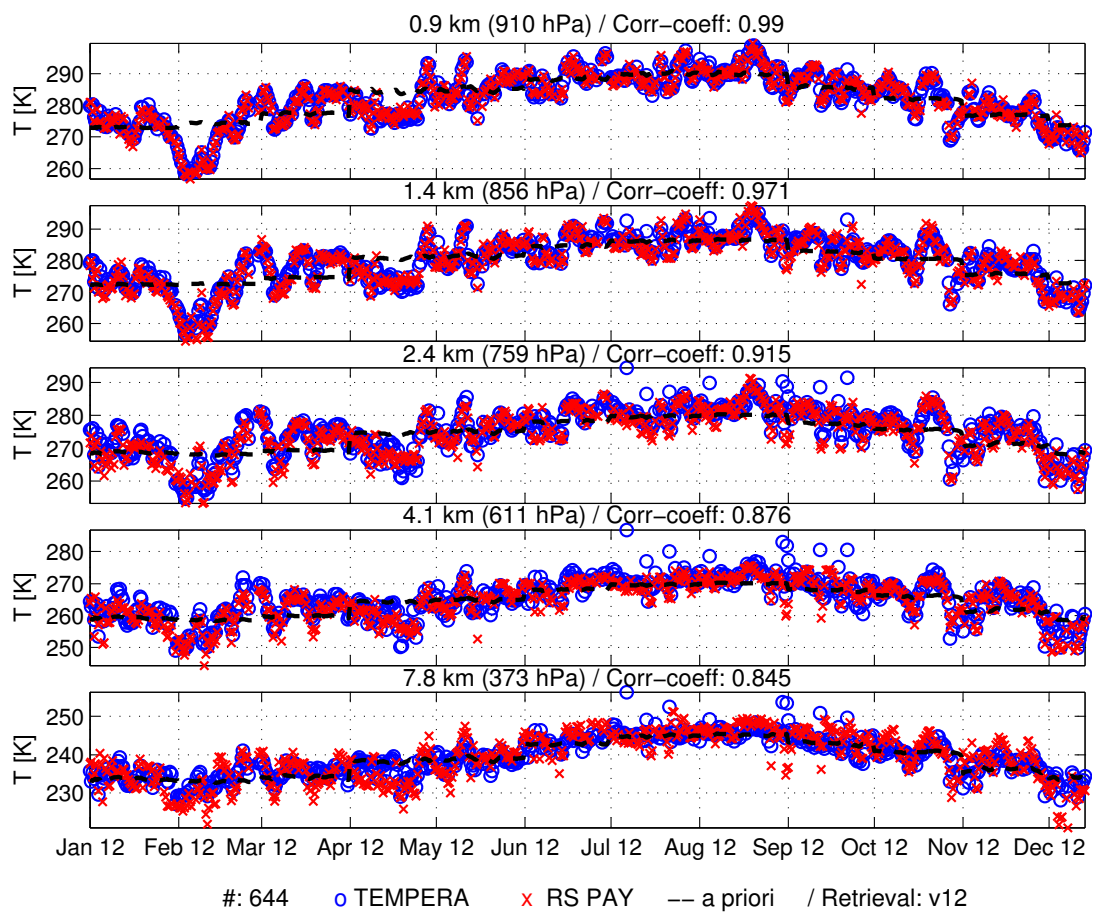

Fig. 11. Time series from 1 January to 13 December 2012 (644 profiles) of tropospheric temperature profiles from TEMPERA (blue) compared with radiosonde data from Payerne (red, regridded to TEMPERA grid) for five different altitude levels. The black dashed line is the a priori.

is more or less the same for the 5 frequencies. This is not true for oxygen, which is strongly dependent on frequency. Furthermore, the figure shows that cloud liquid has a similar absorption coefficient as oxygen in the frequency range from 51 to $53 \mathrm{GHz}$. On the other hand, during clear sky (integrated liquid water, ILW $=0 \mathrm{~mm}$ ) the main part of the absorption and emission in the atmosphere is from oxygen dominating the contribution from water vapor and nitrogen. Further discussion about temperature retrieval during weather conditions with and without clouds will be presented in Sect. 4.2.

\subsection{Weighting functions}

Accurate and rapid calculations of weighting functions (WFs) are important for obtaining stable and fast inversions. The general approach in ARTS to extract WFs is outlined by Buehler et al. (2005); some improvements have since been added. As part of this study, the analytical expressions used for temperature WFs were expanded to also consider local effects caused by the constraint of hydrostatic equilibrium. These resulting WFs cover all relevant aspects of the measurements of concern here, and the extension has drastically improved the calculation speed. See the user guide of ARTS2 (www.sat.ltu.se/arts/docs) for the expressions used and their limitations (e.g. they are not valid for limb sounding).

\subsection{Error analysis}

The total error of a retrieval consists mainly of the observation error due to the measurement noise and uncertainty as well as the smoothing error caused by the vertical smoothing of the retrieval method. The estimations of the observation covariance matrix $\left(\mathbf{S}_{\mathrm{o}}\right)$ and the smoothing covariance matrix $\left(\mathbf{S}_{\mathrm{s}}\right)$ are shown in the following equations (Rodgers, 2000):

$\mathbf{S}_{\mathrm{o}}=\mathbf{D}_{y} \mathbf{S}_{\epsilon} \mathbf{D}_{y}^{\mathrm{T}}$

$\mathbf{S}_{\mathrm{s}}=(\mathbf{A}-\mathbf{I}) \mathbf{S}_{\mathrm{a}}(\mathbf{A}-\mathbf{I})^{\mathrm{T}}$

where $\mathbf{I}$ is the identity matrix. The total error of the observation and of the vertical smoothing is calculated as the square root of the diagonal elements of the covariance matrix $\mathbf{S}_{\mathrm{o}}$ and $\mathbf{S}_{\mathrm{s}}$, respectively.

Additionally there exist the systematic errors. We calculate the systematic errors by considering the estimated uncertainties in the water vapor profile, in the oxygen profile ("spectroscopic error") and in the calibration. This is done by a perturbation approach where we change the respective profiles and the calibration within the estimated limits and compare with the standard retrieval. The used estimated values are listed in Table 4. The total systematic error is calculated as the square root of the sum of the variances from water vapor, oxygen and calibration. 

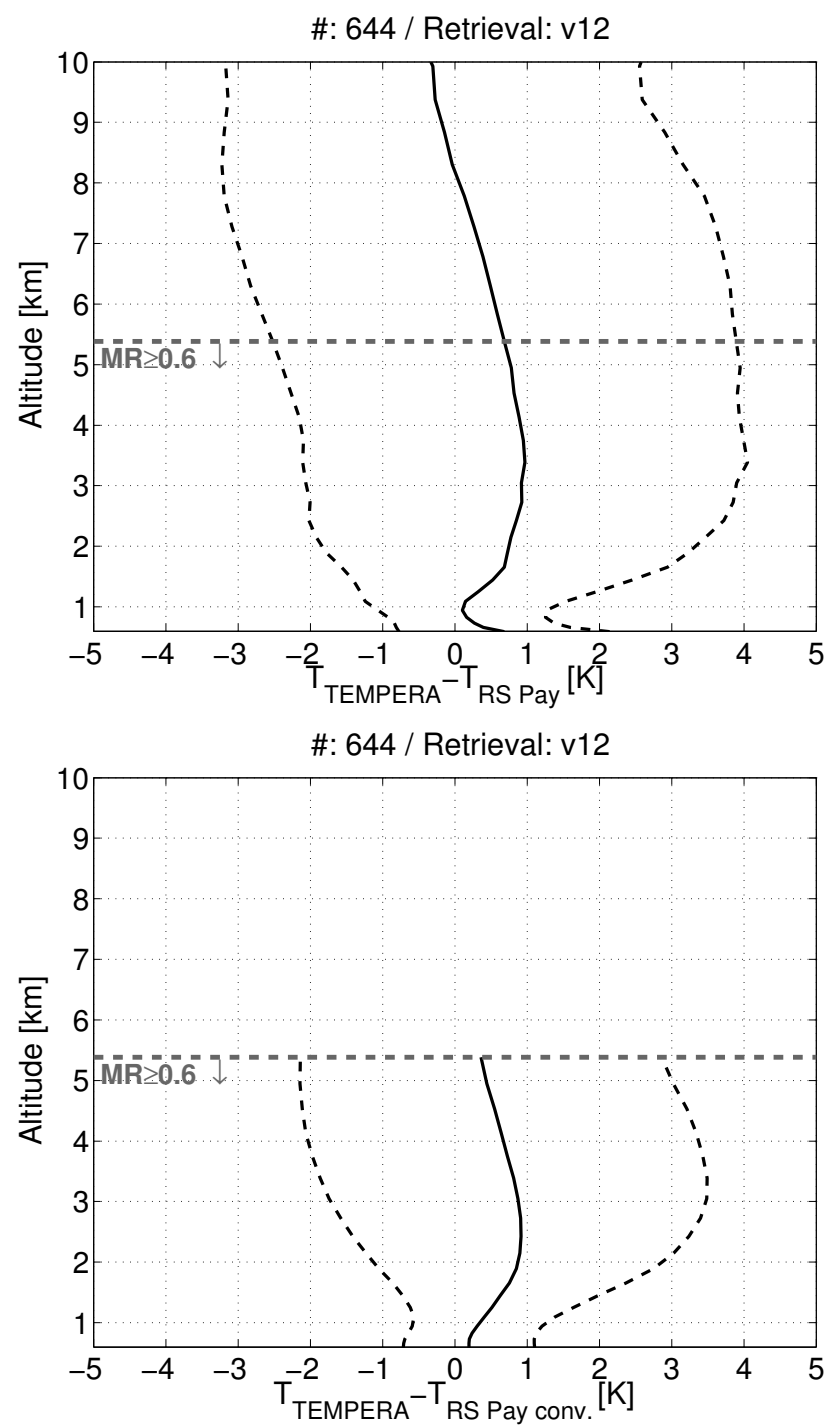

Fig. 12. Comparison of 644 profiles (1 January to 13 December 2012) between TEMPERA and radiosonde data from Payerne over an altitude range from ground $(0.575 \mathrm{~km})$ to $10 \mathrm{~km}$. Plotted are the mean (black line) and plus and minus one standard deviation around the mean (black dashed line) of the differences between TEMPERA and radiosonde data from Payerne. The horizontal dark grey line indicates the region where $\mathrm{MR}=0.6$. Upper panel: TEMPERA compared with unconvolved radiosonde data from Payerne. Lower panel: TEMPERA compared with convolved radiosonde data from Payerne over an altitude region with $\mathrm{MR} \geq 0.6$.

\subsection{Tropospheric retrieval}

As mentioned before, 12 channels are used (Table 2) to retrieve tropospheric temperature profiles. Additionally, we use information from 9 zenith angles $\left(30^{\circ}\right.$ to $70^{\circ}$, every $\left.5^{\circ}\right)$.

The retrieval software Qpack2 (Eriksson et al., 2005) uses a pressure grid for the retrieval calculations. We use the same resolution for the retrieval grid as for the forward model

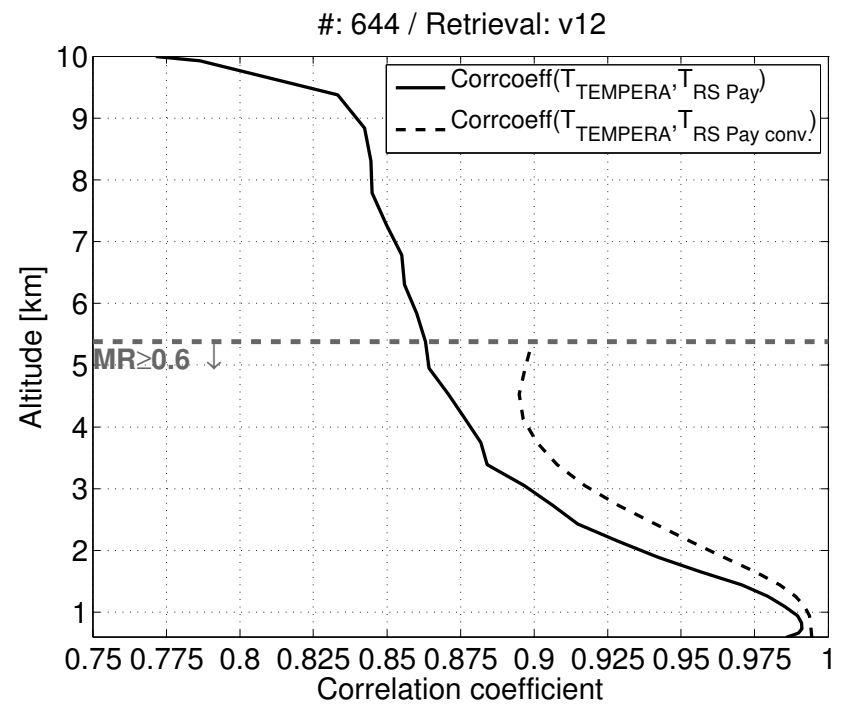

Fig. 13. Correlation coefficient of the comparison of 644 profiles (1 January to 13 December 2012) between TEMPERA and radiosonde data from Payerne over an altitude range from ground $(0.575 \mathrm{~km})$ to $10 \mathrm{~km}$. The horizontal dark grey line indicates the region where $\mathrm{MR}=0.6$. Panel shows correlation coefficient of the comparison between TEMPERA and the unconvolved (black line) and convolved (dashed black line, altitude region with $M R \geq 0.6$ ) radiosonde data is from Payerne.

grid. Our first pressure-grid point is at the surface where our instrument is situated. This pressure value is taken from our weather station at the measurement time. The other grid points are selected in such a way that we have more grid points in the lower troposphere than in the upper troposphere because the measurements contain most information from the lowest layers of the troposphere. Our grid has a resolution of about $100 \mathrm{~m}$ from ground to $1 \mathrm{~km}$, about $300 \mathrm{~m}$ from 1 to $5 \mathrm{~km}$ and about $500 \mathrm{~m}$ from 5 to $10 \mathrm{~km}$.

As an a priori temperature profile, monthly mean radiosonde data from Payerne $\left(46.82^{\circ} \mathrm{N}, 6.95^{\circ} \mathrm{E} ; 491 \mathrm{~m}\right.$ above sea level and $40 \mathrm{~km} \mathrm{~W}$ of Bern) are used. The data are from 1994 to 2011 and the soundings are twice a day at 11:00 and at 23:00 (UT). For the a priori covariance matrix $\mathbf{S}_{\mathrm{a}}$ we use a correlation function decreasing exponentially with a correlation length of $3 \mathrm{~km}$. A standard deviation of $2 \mathrm{~K}$ at ground, decreasing linearly to $1.5 \mathrm{~K}$ at $15 \mathrm{~km}$, is assumed. The observation error is considered in the covariance matrix $\mathbf{S}_{\epsilon}$ as a diagonal matrix. We use the standard deviation of around 15 measurements ( 1 measurement cycle: $1 \mathrm{~min}$ ) at every zenith angle and frequency because every 15 min we retrieve a temperature profile ( 96 profiles per day). The observation error is in a range of 0.4 to $2 \mathrm{~K}$, depending on frequency, zenith angle and weather conditions. 

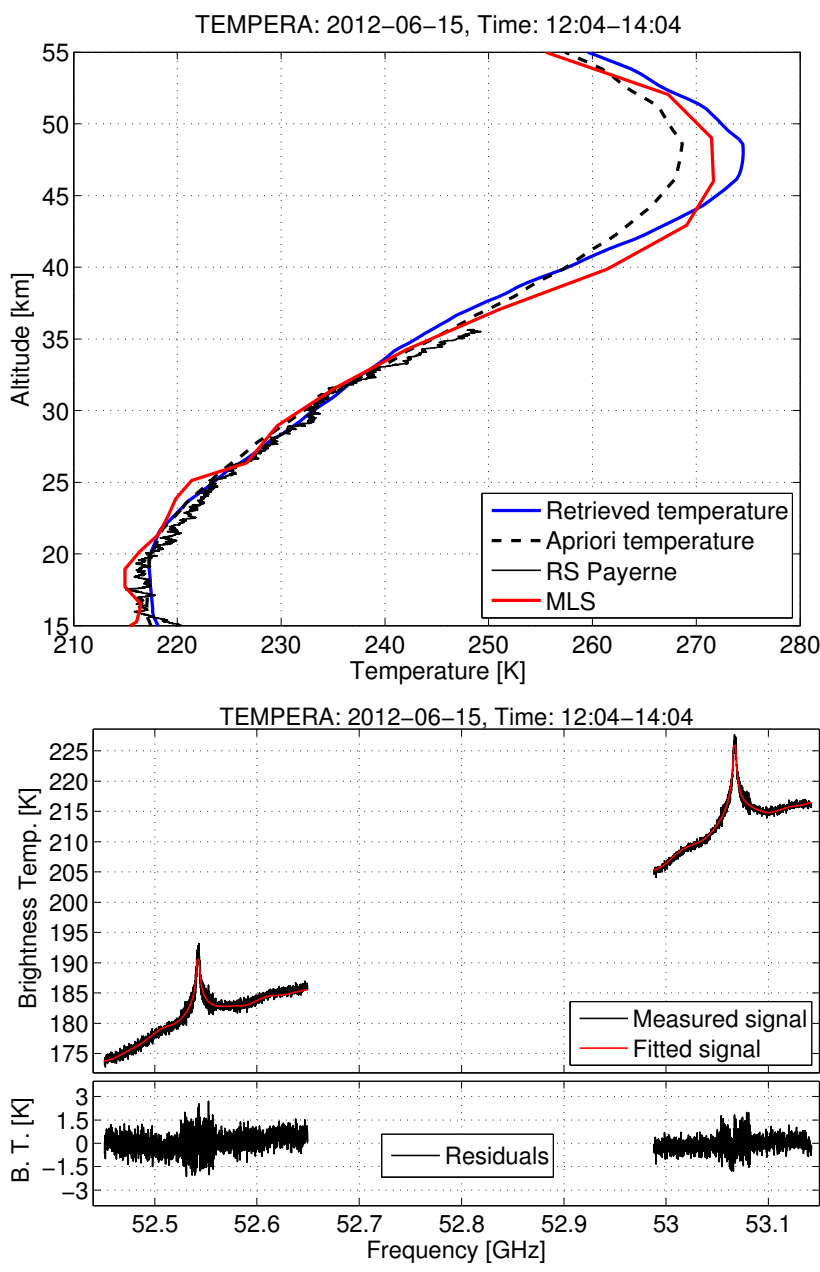

Fig. 14. Measurement of 15 June 2012 from 12:04-14:04 (UT) during clear sky (ILW $=0 \mathrm{~mm}$ ). Upper panel: temperature profile (blue line) retrieved with TEMPERA spectrometer measurements. The a priori profile is the dashed black line. The retrieved profile is compared with radiosonde data from Payerne (black line) and with MLS data (red). Lower panel: Brightness temperatures measured with TEMPERA (black) compared with the forward model brightness temperatures (red) that we received with the retrieval. Low in the panel the residuals are seen. In the forward model $\pm 1 \mathrm{MHz}$ around the two line centers we have no frequencies points in the grid because until now the Zeeman effect has not been incorporated into Qpack2/ARTS2. In the center of the lines $( \pm 16 \mathrm{MHz}, 1000$ channels) we use all channels and on the wings of the line we use a binning of 3 channels for data reduction.

\subsection{Stratospheric retrieval}

The stratospheric temperature profile is retrieved from the measurement of the two emission lines, centered at 52.5424 and $53.0669 \mathrm{GHz}$. We use the two lines at the same time with a bandwidth of $200 \mathrm{MHz}$ around $52.5424 \mathrm{GHz}$ and $160 \mathrm{MHz}$ around $53.0669 \mathrm{GHz}$. With the digital FFT spectrometer we measure at a zenith angle of $30^{\circ}$. In Fig. 3 the simulated spectra at the three different zenith angles 30,50 and $70^{\circ}$ can be
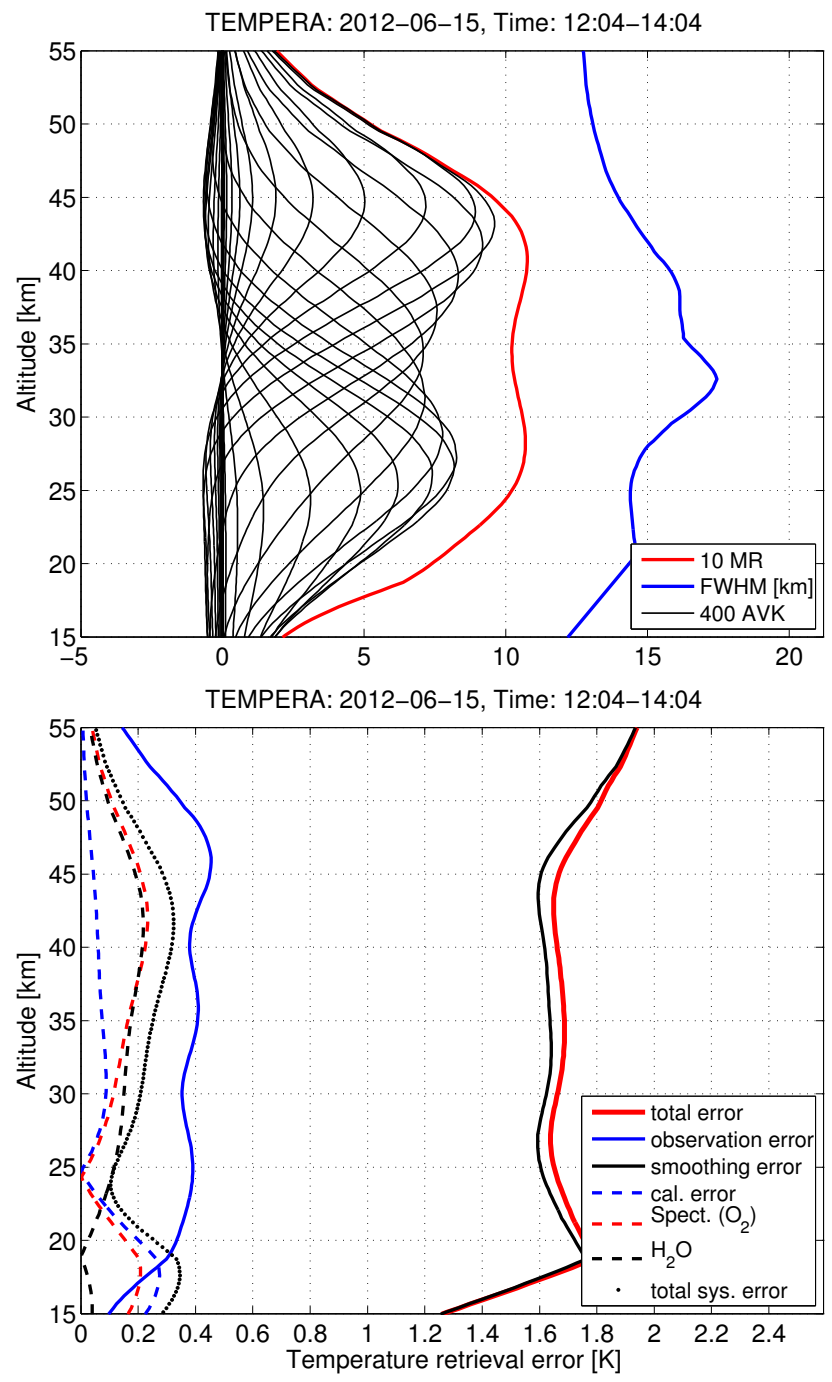

Fig. 15. Measurement of 15 June 2012 from 12:04-14:04 (UT) during clear sky (ILW $=0 \mathrm{~mm}$ ). Upper panel: The averaging kernels (AVK, plotted every 7th) of TEMPERA are shown in this plot together with the measurements response (MR) and the full-width at half-maximum (FWHM, in km). Lower panel: error of the retrieval. The error statistics contain the total error (solid red) consisting of observation error (solid blue) and smoothing error (solid black). The total systematic error (dotted black) contains the uncertainties in the calibration (dashed blue), in the oxygen profile ("spectroscopic error", dashed red) and in the water vapor profile (dashed black).

seen. The results show that the intensity of the emission lines is highest at $\mathrm{za}=30^{\circ}$. Therefore we decided to measure the emission lines at this angle.

During a measurement cycle the integration time with the FFT spectrometer is $15 \mathrm{~s}$. For a temperature profile we integrate the measurement for half an hour because then the noise level is low enough to get good retrievals. This requires two hours of measurement time because only one quarter of the measurement time is spent for the digital 


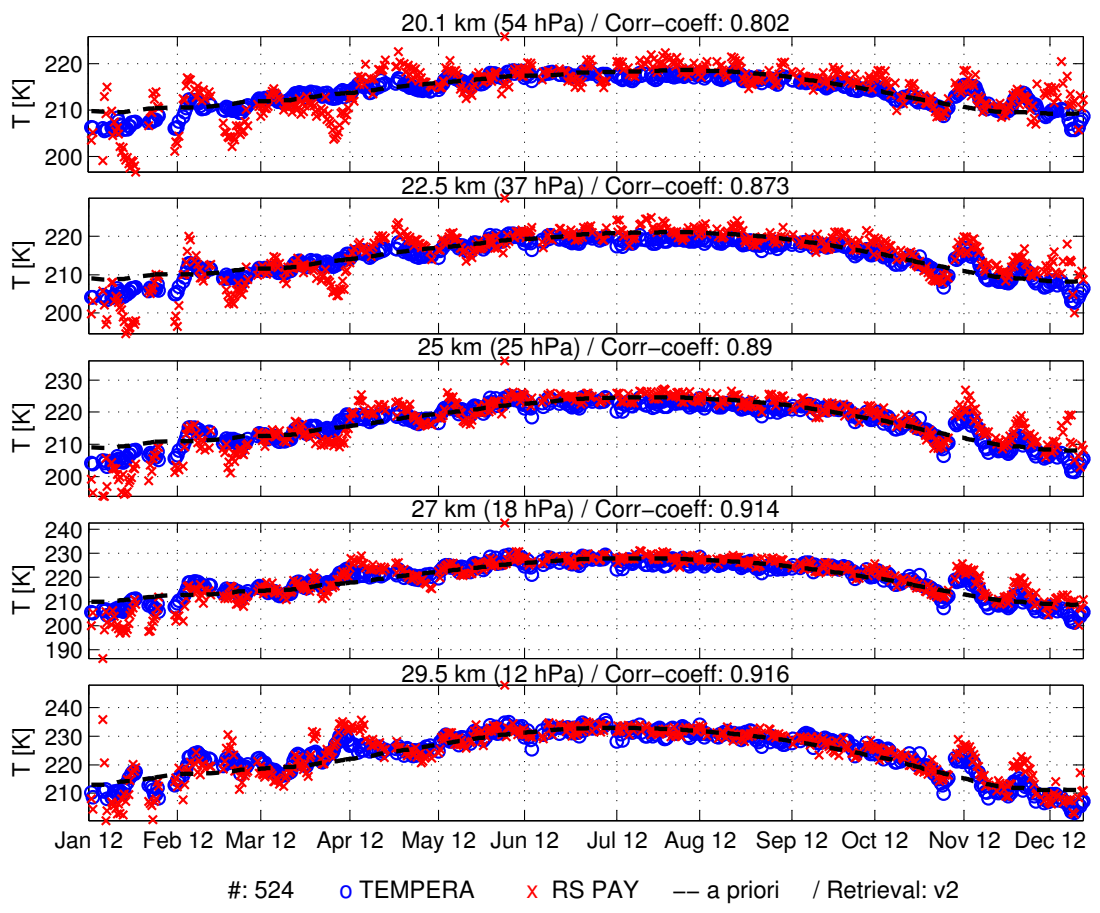

Fig. 16. Time series (524 profiles) of stratospheric temperature profiles from TEMPERA (blue) compared with radiosonde data from Payerne (red, regridded to TEMPERA grid) for five different altitude levels. The black dashed line is the a priori.

FFT spectrometer. The remaining period of the measurement TEMPERA measures at $\mathrm{za}=35-70^{\circ}$ with the filterbank only (see also Sect. 2.3). For the forward model we use a vertical grid with a resolution of about $350 \mathrm{~m}$. The retrieval grid has the same vertical resolution. Further in the forward model $\pm 1 \mathrm{MHz}$ around the two line centers we have no frequency points in the grid because the Zeeman effect is not yet fully incorporated into Qpack2/ARTS2. In the center of the lines $( \pm 16 \mathrm{MHz}, 1000$ channels $)$ we use all channels, and on the wings of the line we use a binning of 3 channels for data reduction.

As a temperature a priori profile from ground to about $15 \mathrm{~km}$ we use the monthly mean of radiosonde data from Payerne from 1994 to 2011. Above, a climatology of the Microwave Limb Sounder (MLS) data (Aura satellite) is used. For the a priori covariance matrix $\mathbf{S}_{\mathrm{a}}$ we use a correlation function decreasing exponentially with a correlation length of $3 \mathrm{~km}$. A standard deviation of $2 \mathrm{~K}$ is assumed. The observation error (residual) is considered in the covariance matrix $\mathbf{S}_{\epsilon}$ as a diagonal matrix. The residual is the difference between the integrated spectra and the fit of the spectra. Under regular conditions the observation error is in a range from 0.5 to $1.5 \mathrm{~K}$. Around $52.5424 \mathrm{GHz}$ (first line) the noise is higher than around at $53.0669 \mathrm{GHz}$ (second line), as shown in Fig. 4.

We retrieve a temperature profile every $2 \mathrm{~h}$, resulting in 12 profiles per day. To avoid effects due to clouds the stratospheric retrieval is done for conditions with ILW $\leq 0.1 \mathrm{~mm}$.

\section{Temperature profiles: results}

\subsection{Introduction}

Here we present an analysis of temperature retrievals from TEMPERA over almost one year, during the period from 1 January to 13 December 2012. The data consist of 2929 stratospheric profiles and 33021 tropospheric profiles. The whole data set, covering the height range from ground to $50 \mathrm{~km}$, can be seen in Fig. 6. The merging of the two independent data sets was done in a way that we use the tropospheric data from ground to $14 \mathrm{~km}$ and the stratospheric data from 14 to $50 \mathrm{~km}$. Because of the different time resolutions we had to adapt the stratospheric data to the time axis of the tropospheric data. There was an interpolation in time necessary. The white lines indicate the measurement response $\mathrm{MR}=0.6$. The altitude range with MR $\geq 0.6$ is from ground to $5-6 \mathrm{~km}$ (troposphere) and from 18 to $48 \mathrm{~km}$ (stratosphere). The tropospheric data are for all weather conditions, and the stratospheric data are for conditions with ILW $\leq 0.1 \mathrm{~mm}$ to avoid effects due to clouds. The information about clouds (ILW) are from the radiometer TROWARA (TRopospheric WAter vapor RAdiometer) (Mätzler and Morland, 2009), which is installed next to TEMPERA, measuring the radiation from the sky in the same direction at 21, 22 and $31 \mathrm{GHz}$.

More details about the tropospheric and stratospheric temperature profiles will follow in the next sections. Furthermore, comparison between the data of TEMPERA and radiosonde and satellites data will be discussed. All correlation 

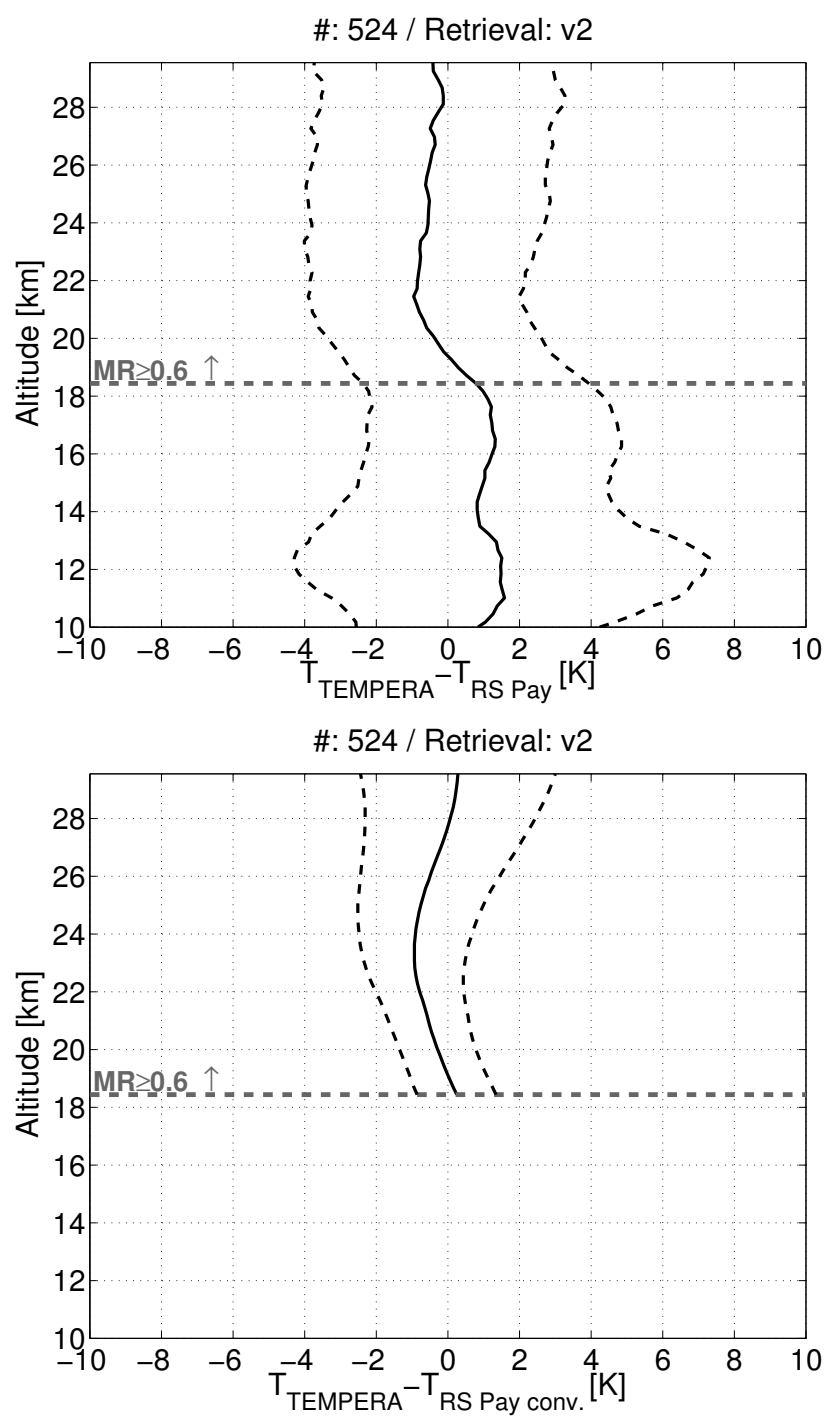

Fig. 17. Comparison of 524 profiles (1 January to 13 December 2012) between TEMPERA and radiosonde data from Payerne over an altitude range from $10 \mathrm{~km}$ to about $29 \mathrm{~km}$. Plotted are the mean (black line) and plus and minus one standard deviation around the mean (black dashed line) of the difference between TEMPERA and radiosonde data from Payerne. The horizontal dark grey line indicates the region where $M R=0.6$. Upper panel: TEMPERA compared with unconvolved radiosonde data from Payerne. Lower panel: TEMPERA compared with convolved radiosonde data from Payerne over an altitude region with $\mathrm{MR} \geq 0.6$.

coefficients of the coincident profiles displayed in this paper have a confidence level above $95 \%$.

\subsection{Tropospheric temperature profiles}

\subsubsection{Clear sky measurements}

Figure 7 shows a typical result of a temperature profile (upper plot) at times without liquid water compared with the profiles obtained by a nearby radiosonde site and the a priori profile. The corresponding brightness temperatures (lower plot) from 14 November 2011 at 11:00 (UT) are also shown. In this case we use all 12 channels and 9 zenith angles, with a total of 108 measured brightness temperatures.

At this time point an inversion between $1000 \mathrm{~m}$ and about $3000 \mathrm{~m}$ was present. Nevertheless the retrieved temperature profile from TEMPERA measurements agrees well with the radiosonde profile from Payerne and the weather stations from Bern and Zimmerwald $\left(46.88^{\circ} \mathrm{N}, 7.47^{\circ} \mathrm{E} ; 905 \mathrm{~m}\right.$ above sea level and $10 \mathrm{~km} \mathrm{~S}$ of Bern).

The forward model brightness temperatures, calculated for the retrieved profile, agree well with the measured brightness temperatures for all channels. The absolute difference between measured and forward model brightness temperatures (residuals) is between 0.05 and $1.2 \mathrm{~K}$. The averaging kernels, the height resolution (FWHM of the averaging kernels) and the measurement response are shown in Fig. 8. The height resolution in the first kilometer is about $300 \mathrm{~m}$. From 1 to $10 \mathrm{~km}$ the height resolution increases to around $5 \mathrm{~km}$.

The retrieval error, calculated with Eqs. (14) and (15), and the systematic errors are shown in Fig. 8. The retrieval error is less than $0.5 \mathrm{~K}$ from ground to $1 \mathrm{~km}$ and then increases linearly to $1.5 \mathrm{~K}$ at $10 \mathrm{~km}$. It is also seen that the observation error is much smaller than the smoothing error. The total systematic error is between 0.5 and $1.5 \mathrm{~K}$ in the altitude range from ground to $10 \mathrm{~km}$.

This example shows that during clear sky we get good results compared with the radiosondes and weather stations from ground up to $7 \mathrm{~km}$ with a measurement response higher than 0.6. From 7 to $10 \mathrm{~km}$ the measurement response is smaller than 0.6 and therefore more information from the a priori profile is used than from the measurements.

\subsubsection{Measurements with cloudy sky}

To retrieve temperature profiles during cloudy sky the lowest 4 channels between $51.25-52.85 \mathrm{GHz}$ are not taken into account in the calculations due to the unknown cloud influence shown in Fig. 5. We choose a threshold of ILW $=0.025 \mathrm{~mm}$ in order to use only 8 channels. Below this threshold value the retrieval takes into account all 12 channels. At the moment we do not take into account the liquid water (clouds) in the forward model. With this simple but effective method we get reasonable results.

A typical result of a temperature profile from 14 November 2011 at 23:00 (UT) with ILW $=0.1 \mathrm{~mm}$ is shown in Fig. 9. This measurement contains 8 frequencies (channels 5-12: 53.35-57 GHz) and 9 zenith angles providing 72 measured brightness temperatures (see also Fig. 9). The forward model brightness temperatures agree with the measured brightness temperatures, with an absolute difference between measured and forward model brightness temperatures (residuals) between 0.05 and $1.8 \mathrm{~K}$. Also, the temperature profile from TEMPERA agrees with the radiosonde data 


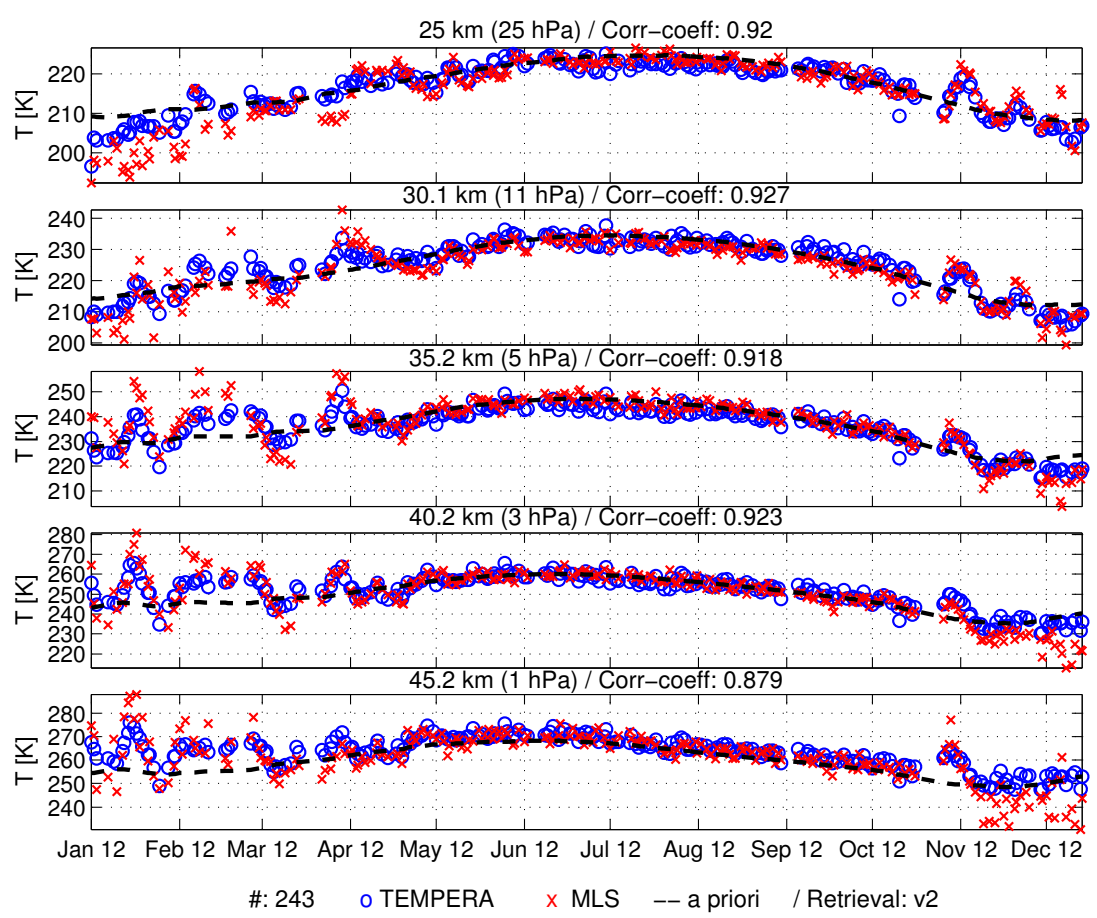

Fig. 18. Time series ( 243 profiles) of stratospheric temperature profiles from TEMPERA (blue) compared with MLS data (red, regridded to TEMPERA grid) for five different altitude levels. The black dashed line is the a priori.

from Payerne and the weather stations from Bern and Zimmerwald. The best agreements are in the altitude range from ground to about $2.5 \mathrm{~km}$.

The averaging kernels, the height resolution (FWHM of the averaging kernels) and the measurement response are shown in Fig. 10. The height resolution is similar to resolution for clear sky. During cloudy sky the measurement response is higher than 0.6 up to about $6 \mathrm{~km}$, i.e. slightly less than during clear sky, because the unused channels carry information about the upper troposphere.

The retrieval error, calculated with Eqs. (14) and (15), is shown in Fig. 10. The retrieval error is also similar to clear sky measurements. The total systematic error is between 0.5 and $0.9 \mathrm{~K}$ in the altitude range from ground to $10 \mathrm{~km}$.

\subsubsection{Comparison with radiosonde data over time}

We compared the TEMPERA tropospheric temperature profiles with the radiosonde data from Payerne $(40 \mathrm{~km} \mathrm{~W}$ of Bern) over the period from 1 January to 13 December 2012 during all weather conditions. Payerne is the closest radiosonde station to Bern. Balloons very often fly in direction to Bern, which makes the difference in location even smaller. The comparison consists of 644 profiles. The data are restricted to cases with near time-coincident sounding and retrieval profiles (two cases per day). Figure 11 shows a time series at 5 altitude levels. We observe an excellent agreement below altitudes of about $1.5 \mathrm{~km}$ with a CC (correlation coefficient) $\mathrm{CC} \geq 0.97$. From $1.5 \mathrm{~km}$ to about $5 \mathrm{~km}$ the results are still well correlated with $\mathrm{CC} \geq 0.86$. From 5 to $10 \mathrm{~km}$ the TEMPERA data agree with the data from radiosonde with a CC between 0.77 and 0.86 . The mean and the standard deviation of the difference $T_{\text {TEMPERA- }} T_{\text {RS PAY }}$ are shown in Fig. 12 over the altitude range from ground to $10 \mathrm{~km}$. This plot also shows that the best agreement is from ground to about $1.5 \mathrm{~km}$. The mean difference is between -0.5 and $+1 \mathrm{~K}$ over the whole altitude range. The standard deviation is around $1 \mathrm{~K}$ from ground to $1.5 \mathrm{~km}$ and then increases to nearly $3 \mathrm{~K}$ at $3 \mathrm{~km}$ and remains constant at this value until $10 \mathrm{~km}$. A similar behavior of the mean value and standard deviation is seen in the comparison between TEMPERA data and convolved data of radiosondes from Payerne (see also Fig. 12, lower panel). The agreements are better in these data. The correlation coefficient of all levels for the unconvolved and convolved data are shown in Fig. 13.

In Fig. 11 an interesting period in the data set is during the first half of February 2012 over an altitude range from ground to about $2.5 \mathrm{~km}$. During this time in Switzerland there was a strong cooling from about 280 to $260 \mathrm{~K}$ at ground. A further interesting case was a warming during August 2012 with a temperature of almost $290 \mathrm{~K}$ at $2.5 \mathrm{~km}$. Both effects were measured with TEMPERA and also with radiosonde data from Payerne.

\subsection{Stratospheric temperatures profiles}

A typical retrieved stratospheric temperature profile is seen in Fig. 14 for 15 June 2012 from 12:04 to 14:04 (UT). Over 

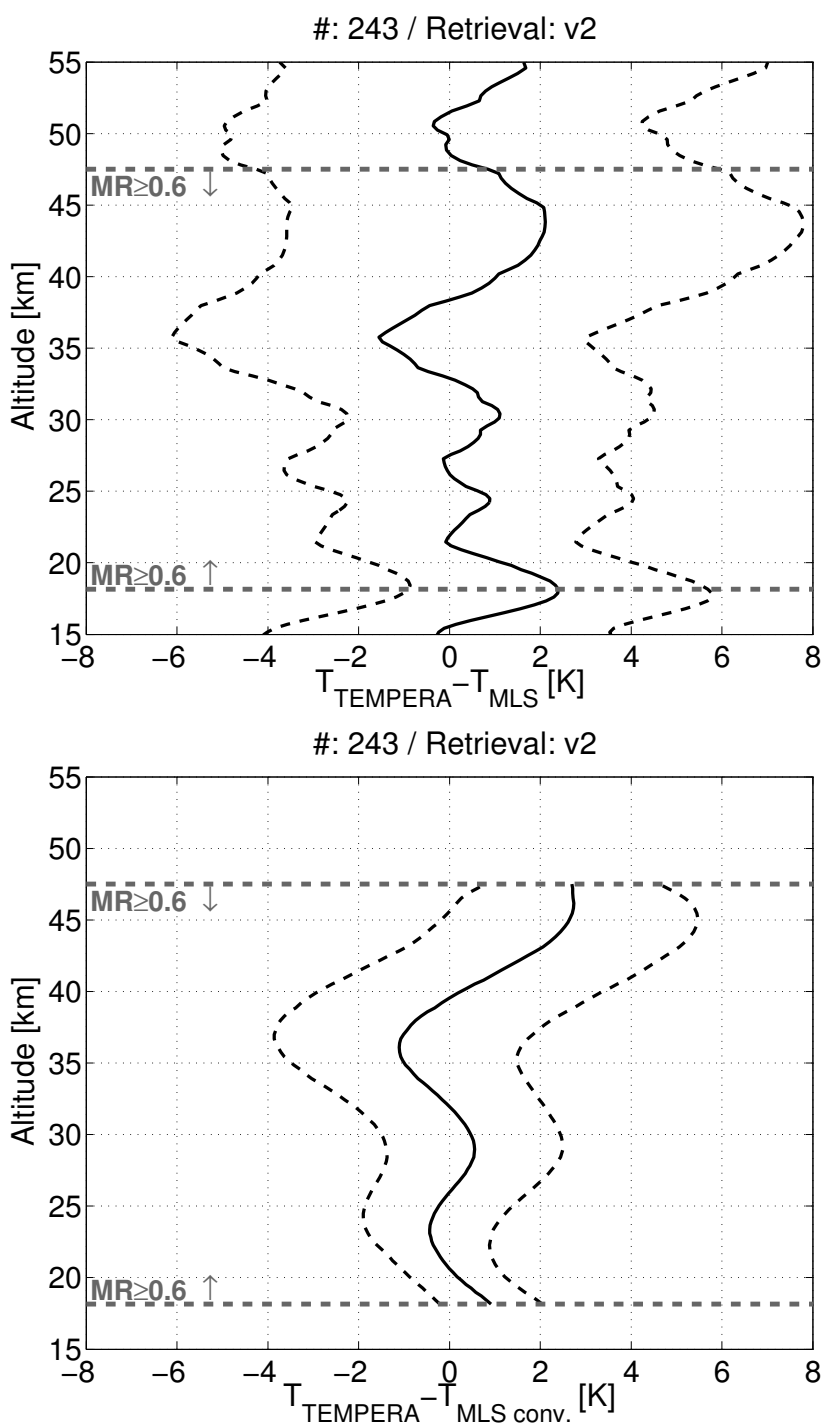

Fig. 19. Comparison of 243 profiles (1 January to 13 December 2012) between TEMPERA and MLS data over an altitude range from $15 \mathrm{~km}$ to about $55 \mathrm{~km}$. Plotted are the mean (black line) and plus and minus one standard deviation around the mean (black dashed line) of the difference between TEMPERA and MLS data. The horizontal dark grey lines indicate the region where $\mathrm{MR}=0.6$. Upper panel: TEMPERA compared with unconvolved MLS data. Lower panel: TEMPERA compared with convolved MLS data over an altitude region with $\mathrm{MR} \geq 0.6$.

an altitude range from $20-45 \mathrm{~km}$ the profile agrees well with other measurements, i.e. satellite data from Aura/MLS and the radiosonde data from Payerne. The forward model brightness temperatures agree well with the measured brightness temperatures excepting around the line center. This is because of the Zeeman effect, which has not yet been incorporated into the forward model. The residuals (see lower panel of Fig. 14) are between -1.5 and $1.5 \mathrm{~K}$.
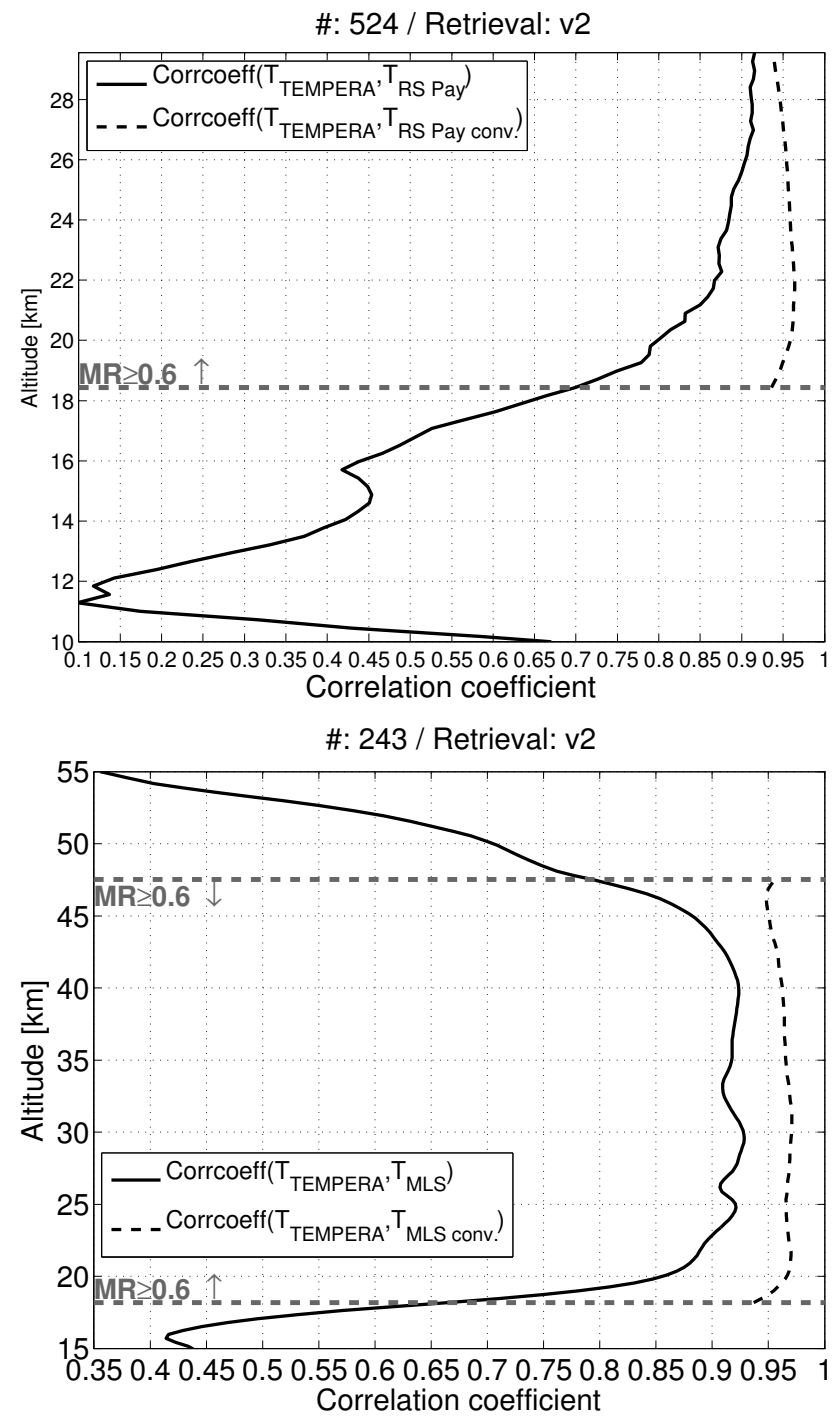

Fig. 20. Correlation coefficient of the comparison between TEMPERA and radiosonde data from Payerne (upper panel, 524 profiles) and MLS data (lower panel, 243 profiles) during the period from 1 January to 13 December 2012. The horizontal dark grey lines indicate the region where $\mathrm{MR}=0.6$. Panels show correlation coefficient of the comparison between TEMPERA and the unconvolved (black line) and convolved data (dashed black line, altitude region with $\mathrm{MR} \geq 0.6$ ).

The averaging kernels, the height resolution (FWHM of the averaging kernels) and the measurement response are shown in Fig. 15. The height resolution is about $15 \mathrm{~km}$. The measurement response higher than 0.6 is in an altitude range from 18 to $48 \mathrm{~km}$. The retrieval error, calculated with Eqs. (14) and (15), is shown in Fig. 15. The total error is between 1.6 and $1.8 \mathrm{~K}$ in the altitude range of 18 to $48 \mathrm{~km}$. Again, it is seen that the observation error is much smaller than the smoothing error. The total systematic error is between 0.1 and $0.35 \mathrm{~K}$ in the altitude range of 18 to $48 \mathrm{~km}$. 


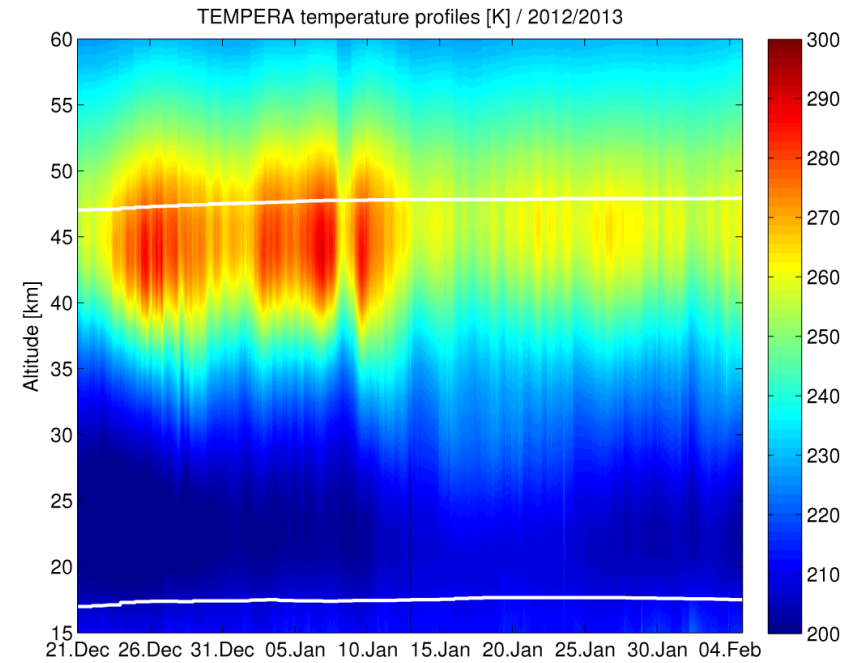

Fig. 21. Retrieved temperature profiles from 15 to $60 \mathrm{~km}$ from 21 December 2012 to 4 February 2013 (46 days). The white lines indicate the region where $\mathrm{MR}=0.6$.

\subsubsection{Comparison with radiosonde and satellite data over time}

We compared the TEMPERA stratospheric temperature profiles with the radiosonde data from Payerne and with MLS data over the period from 1 January to 13 December 2012 during weather conditions with ILW $\leq 0.1 \mathrm{~mm}$. The comparison between TEMPERA data and radiosondes from 10 to $29 \mathrm{~km}$ consists of 524 profiles. The data are restricted to cases with near time-coincident sounding and retrieval profiles (two cases per day). Figure 16 shows the time series at 5 levels. The plot shows that, apart from some exceptions, the time evolution in temperature of both measurements is similar. The best agreement is found at altitudes between 25 and $29 \mathrm{~km}$ with a CC between 0.89 and 0.916 . The mean and the standard deviation of the difference $T_{\text {TEMPERA }}-T_{R S}$ PAY with unconvolved and convolved data are shown in Fig. 17. The mean difference is between -1 and $1 \mathrm{~K}$, and the standard deviation is less than $3 \mathrm{~K}$ for an altitude range from 18 to $29 \mathrm{~km}$. Again, the comparison is better with convolved data (see also Fig. 17, lower panel). The correlation coefficient over all levels with and without convolved data are plotted in Fig. 20 in the upper panel.

Another comparison is obtained from MLS data with 243 profiles. The criterion for a collocation of a MLS profile with the measurement site is $\pm 1^{\circ}( \pm 110 \mathrm{~km})$ in latitude and $\pm 5^{\circ}( \pm 460 \mathrm{~km})$ in longitude. The plotted data are restricted to cases with near time-coincident MLS profiles and TEMPERA profiles. Figure 18 shows the time series at 5 levels from 25 to $45 \mathrm{~km}$ with a $\mathrm{CC}$ between 0.87 and 0.92 . Also, here we see that the time evolution in temperature is similar for both instruments. The mean of the difference $\mathrm{T}_{\text {TEMPERA- }}$ $\mathrm{T}_{\mathrm{MLS}}$ (see Fig. 19) varies between $0 \mathrm{~K}$ and $1 \mathrm{~K}$ from 20 to
$30 \mathrm{~km}$, followed by a dip to $-2 \mathrm{~K}$ at $35 \mathrm{~km}$, then increases to around $2 \mathrm{~K}$ at $45 \mathrm{~km}$. The standard deviation of this comparison is around $2.5 \mathrm{~K}$ from 20 to $35 \mathrm{~km}$ and around $4.5 \mathrm{~K}$ above $35 \mathrm{~km}$. The agreement between the TEMPERA data and the MLS convolved data are better with a $C C \geq 0.95$ over altitude levels from 18 to $48 \mathrm{~km}$ (MR $\geq 0.6$ ). The correlation coefficient over all levels with and without convolved data are plotted in Fig. 20 in the lower panel.

Both comparisons show that TEMPERA performs well in the stratosphere. The results are best in the range from 25 to $40 \mathrm{~km}$ with $\mathrm{CC} \geq 0.9$ and with $\mathrm{CC} \geq 0.95$ for convolved data.

An interesting period was observed with TEMPERA and MLS in the beginning of January 2012 (Fig. 18). Both instruments measured a warming from about 260 to $280 \mathrm{~K}$ at an altitude of $45 \mathrm{~km}$ within some days. During the end of October and in the beginning of November there was a warming of more than $10 \mathrm{~K}$ at levels between 20 to $30 \mathrm{~km}$. All three instruments (radiosonde, MLS and TEMPERA) measured these effects.

\subsubsection{Sudden stratospheric warming (SSW) over Bern during winter 2012/2013}

At the end of 2012 and in the beginning of 2013 a sudden stratospheric warming (SSW) occurred that was observed over Bern. During a SSW the temperature in the stratosphere increases by several tens of degrees within a very short time. This type of warming was first observed by Scherhag (1952). SSW events over Bern were observed in 2008 and 2010. Flury et al. (2009) and Scheiben et al. (2012) reported the influence of these temperature increases on ozone and water vapor in the stratosphere, measuring with ground-based microwave radiometers and using temperature profiles from ECMWF or MLS to investigate the SSW.

We measured the recent 2012 SSW event with the new ground-based radiometer TEMPERA. The time series from 21 December 2012 to 4 February 2013 (46 days) is shown in Fig. 21. In this plot we see a strong warming by about $30 \mathrm{~K}$ at an altitude of $40 \mathrm{~km}$ in the time period from 21 December 2012 to 25 December 2012. The warming stayed with temperatures between 250 to $290 \mathrm{~K}$ until 12 January 2013 over the altitude range of 40 to $50 \mathrm{~km}$. The warmest region with $290 \mathrm{~K}$ was near $45 \mathrm{~km}$. After this time period the temperature decreased to temperatures between 240 to $265 \mathrm{~K}$.

This example shows that with TEMPERA it is possible to measure such interesting stratospheric events and to study local phenomena at mesoscale. Together with data from our other radiometers for ozone and water vapor we are now in an excellent position to study such interesting SSW events with high time resolution. 


\section{Conclusions}

TEMPERA, the measurement instrument used in this study, is a new ground-based radiometer for tropospheric and stratospheric temperature profiles. For the troposphere a filterbank with 12 channels $(51-57 \mathrm{GHz})$ is used and for the stratosphere two emission lines at 52.5424 and $53.0669 \mathrm{GHz}$ are measured with a digital FFT spectrometer. This radiometer is the first instrument to measure temperature profiles from ground to about $50 \mathrm{~km}$ with a high sensitivity from ground to $6 \mathrm{~km}$ and from 18 to $48 \mathrm{~km}$. TEMPERA also acquired information from 6 to $18 \mathrm{~km}$ but with reduced sensitivity, meaning we used more a priori information for the temperature profiles at these levels.

First validations of TEMPERA data with radiosonde and satellite data showed good agreements. The comparison with the radiosonde station in Payerne ( $40 \mathrm{~km} \mathrm{~W}$ of Bern) is not optimal because of lateral distance. A better comparison would be to measure with TEMPERA at Payerne, which is planned for future work.

The comparison of 644 profiles in the troposphere with radiosonde showed that the mean difference of the data is between -0.5 and $1 \mathrm{~K}$ with a $\mathrm{CC}$ (correlation coefficient) $\mathrm{CC} \geq 0.93$ (convolved data: $\mathrm{CC} \geq 0.96$ ) from ground to $2 \mathrm{~km}$, a $\mathrm{CC} \geq 0.86$ (convolved data: $\mathrm{CC} \geq 0.89$ ) from 2 to $6 \mathrm{~km}$ and from 6 to $10 \mathrm{~km}$ the $\mathrm{CC}$ is between 0.77 and 0.86 .

The comparison in the stratosphere with radiosonde (524 profiles) and satellite data (243 profiles) are also good. In the stratosphere the mean difference is between -2 and $2 \mathrm{~K}$. The results are best in the range from 25 to $40 \mathrm{~km}$ with $\mathrm{CC} \geq 0.9$ and with $\mathrm{CC} \geq 0.95$ for convolved data. During cloudy sky there is a simple way to improve the tropospheric retrieval, which is to only use the higher frequencies above $53 \mathrm{GHz}$. For the stratospheric temperature retrieval we limited the retrievals to ILW $\leq 0.1 \mathrm{~mm}$.

The upper height limit of the retrieval is at $50 \mathrm{~km}$ due to the Zeeman effect. This effect is also seen in the measurements with the digital FFT spectrometer as a line broadening near its center.

The data in this paper were produced with two independent retrievals for the troposphere and the stratosphere and then merged together in a color plot over an altitude range from ground to $50 \mathrm{~km}$. The benefit of this method is that we were able to use the full time resolution of the two retrievals (troposphere: $15 \mathrm{~min}$, stratosphere: $2 \mathrm{~h}$ ).

In the future our goal is to combine the two data sets to a single retrieval in order to have one single profile from ground to $50 \mathrm{~km}$. For future work we plan to investigate in more detail the retrieval under cloudy conditions (liquid clouds only). Furthermore, we aim to measure the Zeeman effect with a narrow-band software-defined radio (SDR) spectrometer. The effect will be incorporated into the forward model to improve the stratospheric temperature retrieval.
Acknowledgements. This work has been supported by the Swiss National Science Foundation grant number 200020-146388. Balloon sounding profiles were kindly provided by MeteoSwiss, Payerne. We thank NASA for making Aura MLS data available.

Edited by: J. Notholt

\section{References}

Alpers, M., Eixmann, R., Fricke-Begemann, C., Gerding, M., and Höffner, J.: Temperature lidar measurements from 1 to $105 \mathrm{~km}$ altitude using resonance, Rayleigh, and Rotational Raman scattering, Atmos. Chem. Phys., 4, 793-800, doi:10.5194/acp-4-7932004, 2004.

Anderson, G. P., Clough, S. A., Kneizys, F. X., Chetwynd, J. H., and Shettle, E. P.: AFGL atmospheric constituent profiles (0-120 km), Tech. Rep. TR-86-0110, AFGL, 1986.

Aumann, H. H., Chahine, M. T., Gautier, C., Goldberg, M. D., Kalnay, E., McMillin, L. M., Revercomb, H., Rosenkranz, P. W., Smith, W. L., Staelin, D. H., Strow, L. L., and Susskind, J.: AIRS/AMSU/HSB on the Aqua Mission: Design, Science Objectives, Data Products, and Processing Systems, IEEE T. Geosci. Remote., 41, 253-264, doi:10.1109/TGRS.2002.808356, 2003.

Bleisch, R., Kämpfer, N., and Haefele, A.: Retrieval of tropospheric water vapour by using spectra of a $22 \mathrm{GHz}$ radiometer, Atmos. Meas. Tech., 4, 1891-1903, doi:10.5194/amt-4-1891-2011, 2011.

Buehler, S. A., Eriksson, P., Kuhn, T., von Engeln, A., and Verdes, C.: ARTS, the Atmospheric Radiative Transfer Simulator, J. Quant. Spectrosc. Ra., 91, 65-93, doi:10.1016/j.jqsrt.2004.05.051, 2005.

Crewell, S., Czekala, H., Löhnert, U., Simmer, C., Rose, T., and Zimmermann, R.: Microwave Radiometer for Cloud Cartography, A22-channel ground-based microwave radiometer for atmospheric research., Radio Sci., 36, 621-638, 2001.

Eriksson, P., Jiménez, C., and Buehler, S. A.: Qpack, a general tool for instrument simulation and retrieval work, J. Quant. Spectrosc. Ra., 91, 47-64, doi:10.1016/j.jqsrt.2004.05.050, 2005.

Eriksson, P., Buehler, S. A., Davis, C. P., Emde, C., and Lemke, O.: ARTS, the atmospheric radiative transfer simulator, Version 2, J. Quant. Spectrosc. Ra., 112, 1551-1558, doi:10.1016/j.jqsrt.2011.03.001, 2011.

Evans, K. D., Melfi, S. H., Ferrare, R. A., and Whiteman, D. N.: Upper tropospheric temperature measurements with the use of a Raman lidar, Appl. Optics, 36, 2594-2602, doi:10.1364/AO.36.002594, 1997.

Feltz, W. F., Smith, W. L., Howell, H. B., Knuteson, R. O., Woolf, H. M., and Revercomb, H. E.: Near-Continuous Profiling of Temperature, Moisture, and Atmospheric Stability Using the Atmospheric Emitted Radiance Interferometer (AERI), J. Appl. Meteorol., 42, 584-597, doi:10.1175/15200450(2003)042<0584:NPOTMA>2.0.CO;2, 2003.

Flury, T., Hocke, K., Haefele, A., Kämpfer, N., and Lehmann, R.: Ozone depletion, water vapor increase, and PSC generation at midlatitudes by the 2008 major stratospheric warming, J. Geophys. Res., 114, doi:10.1029/2009JD011940, 2009.

Hajj, G., Kursinski, E., Romans, L., Bertiger, W., and Leroy, S.: A technical description of atmospheric sounding by GPS 
occultation, J. Atmos. Solar-Terrest. Phys., 64, 451-469, doi:10.1016/S1364-6826(01)00114-6, 2002.

Liebe, H., Hufford, G., and Cotton, M.: Propagation modeling of moist air and suspended water/ice particles at frequencies below $1000 \mathrm{GHz}$. in AGARD 52nd Specialists Meeting of the Electromagnetic Wave Propagation Panel, Palma de Mallorca, Spain, 3.1-3.10, 1993.

Luers, J. K.: Temperature Error of the Vaisala RS90 Radiosonde, J. Atmos. Oceanic Technol., 14, 1520-1532, doi:10.1175/15200426(1997)014<1520:TEOTVR>2.0.CO;2, 1997.

Martin, L., Schneebeli, M., and Mätzler, C.: ASMUWARA, a ground-based radiometer system for tropospheric monitoring, Meteorologische Z., 15, 11-17, doi:10.1127/09412948/2006/0092, 2006.

Mätzler, C. and Morland, J.: Refined Physical Retrieval of Integrated Water Vapor and Cloud Liquid for Microwave Radiometer Data, IEEE T. Geosci. Remote Sens., 47, 1585-1594, 2009.

Murk, A., Treuttel, J., Rea, S., and Matheson, D.: Characterization of a 340GHz Sub-Harmonic IQ Mixer with Digital Sideband Separating Backend, in: Proceedings of the 5th ESA Workshop on Millimetre Wave Technology and Applications, 469-476, ESTEC, Noordwijk, Netherland, 2009.

Remsberg, E. E., Lingenfelser, G., Harvey, V. L., Grose, W., Russell III, J. M., Mlynczak, M. G., Gordley, L., and Marshall, B. T.: On the verification of the quality of SABER temperature, geopotential height, and wind fields by comparison with MET Office assimilated analyses, J. Geophys. Res., 108, 1-10, doi:10.1029/2003JD003720, 2003.

Rodgers, C. D.: Inverse Methods for Atmospheric Soundings, World Scientific Publishing Co Pte. Ltd, 2000.

Rose, T., Crewell, S., Löhnert, U., and Simmer, C.: A network suitable microwave radiometer for operational monitoring of the cloudy atmosphere, Atmos. Res., 75, 183-200, doi:10.1016/j.atmosres.2004.12.005, 2005.

Rosenkranz, P. W.: Absorption of microwaves by atmospheric gases, in: Atmospheric remote sensing by microwave radiometry, edited by: Janssen, M. A., John Wiley \& Sons, 37-90, 1993.

Rosenkranz, P. W.: Water vapor microwave continuum absorption: A comparison of measurements and models, Radio Sci., 33, 919928, 1998.

Ruffieux, D. and Joss, J.: Influence of Radiation on the Temperature Sensor Mounted on the Swiss Radiosonde, J. Atmos. Oceanic Technol., 20, 1576-1582, doi:10.1175/15200426(2003)020<1576:IOROTT>2.0.CO;2, 2003.

Scheiben, D., Straub, C., Hocke, K., Forkman, P., and Kämpfer, N.: Observations of middle atmospheric $\mathrm{H}_{2} \mathrm{O}$ and $\mathrm{O}_{3}$ during the 2010 major sudden stratospheric warming by a network of microwave radiometers, Atmos. Chem. Phys., 12, 7753-7765, doi:10.5194/acp-12-7753-2012, 2012.
Scherhag, R.: Die explosionsartigen Stratosphärenerwärmungen des Spätwinters, 1951-52, Ber. Deut. Wetterdienst, 38, 51-63, 1952.

Shvetsov, A. A., Fedoseev, L. I., Karashtin, D. A., Bol'shakov, O. S., Mukhin, D. N., Skalyga, N. K., and Feigin, A. M.: Measurement of the middle-atmosphere temperature profile using a groundbased spectroradiometer facility, Radiophys. Quantum El., 53, 321-325, 2010.

Smith, W. L., Feltz, W. F., Knuteson, R. O., Revercomb, H. E., Woolf, H. M., and Howell, H. B.: The Retrieval of Planetary Boundary Layer Structure Using GroundBased Infrared Spectral Radiance Measurements, J. Atmos. Oceanic Technol., 16, 323-333, doi:10.1175/15200426(1999)016<0323:TROPBL>2.0.CO;2, 1999.

Ware, R., Carpenter, R., Güldner, J., Liljegren, J., Nehrkorn, T., Solheim, F., and Vandenberghe, F.: A multichannel radiometric profiler of temperature, humidity, and cloud liquid., Radio Sci., 38, 44.1-44.13, doi:10.1029/2002RS002856, 2003.

Waters, J. W.: Ground-based Measurement of Millimetrewavelength Emission by Upper Stratospheric $\mathrm{O}_{2}$, IEEE T. Geosci. Remote., 44, 1075-1092, doi:10.1109/TGRS.2006.873771, 1973.

Waters, J. W., Froidevaux, L., Harwood, R. S., Jarnot, R. F., Pickett, H. M., Read, W. G., Siegel, P. H., Cofield, R. E., Filipiak, M. J., Flower, D. A., Holden, J. R., Lau, G. K. K., Livesey, N. J., Manney, G. L., Pumphrey, H. C., Santee, M. L., Wu, D. L., Cuddy, D. T., Lay, R. R., Loo, M. S., Perun, V. S., Schwartz, M. J., Stek, P. C., Thurstans, R. P., Boyles, M. A., Chandra, K. M., Chavez, M. C., Chen, G. S., Chudasama, B. V., Dodge, R., Fuller, R. A., Girard, M. A., Jiang, J. H., Jiang, Y. B., Knosp, B. W., LaBelle, R. C., Lam, J. C., Lee, K. A., Miller, D., Oswald, J. E., Patel, N. C., Pukala, D. M., Quintero, O., Scaff, D. M., Van Snyder, W., Tope, M. C., Wagner, P. A., and Walch, M. J.: The Earth Observing System Microwave Limb Sounder (EOS MLS) on the Aura satellite, IEEE T. Geosci. Remote., 44, 10751092, doi:10.1109/TGRS.2006.873771, 2006.

Wickert, J., Reigber, C., Beyerle, G., König, R., Marquardt, C., Schmidt, T., Grunwaldt, L., Galas, R., Meehan, T. K., Melbourne, W. G., and Hocke, K.: Atmosphere sounding by GPS radio occultation: First results from CHAMP, Geophys. Res. Lett., 28, 3263-3266, doi:10.1029/2001GL013117, 2001. 